\title{
Risk and Return around the Clock
}

\author{
Felix Fattinger Alexandre Ziegler*
}

April 14, 2015

\begin{abstract}
We investigate price discovery over the 24-hour trading day for equities, currencies, bonds, and commodities. Sizable price discovery occurs around the clock for most assets. For a given asset, intraday risk and return distributions are fairly similar, indicating a broadly constant risk-return-relationship during the day. Although the amount of price discovery varies significantly during the day and differs across assets, price discovery is generally efficient around the clock. Most assets do not exhibit the U-shaped intraday volatility pattern that has been documented for US equities, even if only main trading hours are considered. Intraday spikes in volatility are driven by the open or close of the market for the respective asset or other assets and by macroeconomic announcements. Both diffusion and jump risk are important drivers of intraday volatility patterns, and US macroeconomic news account for a sizable fraction of jump-driven volatility. For some - but not all - assets, the relationship between volume and volatility that can generally be observed during the trading day does not hold at the time of jumps, suggesting that traders anticipate large price moves at the time of scheduled announcements and market depth falls accordingly.
\end{abstract}

Keywords: Price discovery, Market efficiency, Intraday return and volatility patterns, High-frequency data, Jumps

JEL Classification: G14, G15, F3

${ }^{*}$ Both authors are with the University of Zurich. Fattinger: Phone: +41 (0)44 634-4049. E-mail: felix.fattinger@bf.uzh.ch. Postal: Institut für Banking und Finance, Universität Zürich, Plattenstrasse 32, CH-8032 Zürich, Switzerland. Ziegler: Phone: +41 (0)44 634-2732. E-mail: alexandre.ziegler@bf.uzh.ch. Postal: Institut für Banking und Finance, Universität Zürich, Plattenstrasse 14, CH-8032 Zürich, Switzerland. We thank Ramo Gençay and Michel Habib for valuable suggestions. 


\section{Introduction}

How important are news coming from different parts of the world for asset prices, and how is this reflected in the distribution of risk and return during the trading day? While intuition allows making qualitative statements about these issues for some assets, actual figures are unknown. For example, one would expect US equity prices at large to be driven mostly by US macroeconomic news, but to also react - probably to a lesser extent - to macroeconomic news coming out of Europe and Asia. What share of equities' returns and volatility can be attributed to these different sources? Turning to a less intuitive case, what intraday return and volatility patterns should we expect for oil, which is consumed around the world and largely produced in the Middle East and Russia, where political risk can be sizable? How about gold, whose two largest producers are China and Australia, but which is used globally both in industrial applications and as a monetary asset? In this paper we investigate price discovery around the clock for a number of benchmark assets from the main asset classes equities, currencies, bonds, and commodities.

While price discovery has been studied extensively in the literature, around-the-clock analyses have not been possible for most assets (with the exception of currencies) because of limited trading hours. During the last couple of years, however, the trading hours of futures contracts on a number of global benchmark assets have been progressively extended, with some contracts now trading almost 24 hours a day. This recent development offers an unique opportunity to investigate price discovery around the clock. In addition to trading hours that are longer than those of the underlying cash market for most instruments, the use of futures contracts has a number of advantages. First, it allows performing a comprehensive analysis using a unified methodology, thus ensuring that differences in price behavior across assets are not driven by differences in the way the market is organized. Second, trading on futures markets is subject to relatively few institutional or regulatory restrictions; in particular, taking long and short positions is equally easy and short-selling bans cannot be imposed by construction. To our knowledge, this paper is the first comprehensive analysis of price discovery across time zones and asset classes.

Our analysis considers 13 contracts from the asset classes equities, bonds, currencies, and commodities; for the latter we focus on oil and metals. Specifically, we consider the S\&P 500, EuroStoxx 50, and Nikkei equity index futures; the 10-year US Treasury Note, 10-year German Bund, and 10-year Japanese Bond futures; the EUR/USD and JPY/USD currency 
futures; West Texas Intermediate and Brent oil futures; as well as gold, silver, and high-grade copper futures. These contracts are widely regarded as global benchmarks and are all very liquid. By contrast with individual stocks, where after-hours trading volume is typically a small fraction of total volume, most of these contracts have sizable trading volume outside of the underlying cash market's trading hours.

The main findings of our analysis can be summarized as follows. First, sizable price discovery takes place around the clock for almost all assets, but its distribution during the day is considerably different across assets. While the amount of price discovery per unit time is larger when underlying cash markets are open, a large amount of price discovery nonetheless takes place when they are closed. Indeed, adjusted for trading volume, price discovery is higher outside of main trading hours. Generally, the distribution of price discovery during the day is similar for equities and bonds from the same region. Moreover, for a given instrument and even within some asset classes (currencies, oil, and metals), the distribution of risk and return during the day is fairly similar, indicating a broadly constant risk-return-relationship during the trading day. Put differently, it is not the case that returns accrue in the morning and risk in the afternoon or vice versa.

Second, although the amount of price discovery varies significantly during the day and across assets, price discovery is quite efficient around the clock for most assets. Nevertheless, efficiency tends to be higher during an asset's main market hours, and there exist short periods where price discovery is inefficient. For most instruments, inefficiency is concentrated before the open of Asian markets and during the first few hours of trading on Asian markets.

Third, while all assets exhibit strong intraday volatility patterns, the precise shapes of these patterns vary substantially. Strikingly, most assets do not exhibit the U-shaped intraday volatility pattern that has been widely documented for US equities, even if only the trading hours of the underlying or pit market are considered. Generally, intraday spikes in volatility occur at four sets of times: (i) at the open or close of the market for the respective asset, (ii) at the open or close of the futures pit for the respective asset, (iii) at the open or close of other markets (both the underlying cash market and markets for other assets), and (iv) at the time of macroeconomic news releases. Most assets react strongly to US macroeconomic news releases and have higher volatility during US trading hours, but also exhibit strong volatility outside of US trading hours. This is in particular the case for metals and currencies. The S\&P 500 is the only asset in our sample that exhibits a clear-cut U- 
shaped volatility pattern, and that pattern only holds during hours when the underlying cash market is open. This observation calls for new theories to explain intraday volatility patterns for around-the-clock markets.

Fourth, when decomposing intraday volatility into its diffusion and jump components, we find both diffusion and jump volatility to be important drivers of overall intraday volatility patterns. The contribution of jumps to overall volatility is substantial, accounting for approximately $5 \%$ to $13 \%$ of total daily return variance. A sizable fraction of jump-driven volatility occurs around US macroeconomic news announcements, affecting all assets in our sample.

Finally, while there is strong comovement between trading volume and volatility during the trading day, the relationship is far from perfect. Volume generally significantly exceeds volatility during US trading hours. Interestingly, the relationship between volume and volatility that can generally be observed during the trading day often does not hold at jump times. Specifically, while both volume and volatility spike at the time of jumps, the difference between the two sometimes does and sometimes does not. This suggests that in some - but not all - markets, traders anticipate large price moves at the time of scheduled announcements and market depth falls accordingly. Furthermore, the opening and closing of stock markets or futures pits tend to be associated with spikes in trading volume that are much larger than the contemporaneous spikes in volatility. Moreover, these spikes in volume are often substantially larger than those associated with price jumps.

The remainder of the paper is organized as follows. Section 2 provides a concise review of the related literature. Section 3 describes the assets that we consider in the study and our dataset. Section 4 analyzes the distribution of returns during the trading day. Section 5 investigates the rate and efficiency of price discovery during the trading day. Section 6 describes intraday volatility patterns, and Section 7 performs a decomposition of intraday volatility into its diffusion and jump components. Section 8 investigates the intraday relationship between trading volume and volatility with particular emphasis on the behavior at jump times. Section 9 concludes. 


\section{Literature Review}

A large literature investigates return and volatility patterns across weekdays and during the trading day. As mentioned above, however, most of this literature only describes intraday risk and return patterns for limited hours - usually between seven and nine depending on the country - during which exchanges are typically open, with price discovery between the close and the open reflected in highly variable overnight returns.

Wood, McInish, and Ord (1985) find unusually high returns and volatilities at the beginning and the end of the trading day for NYSE stocks. Similar U-shaped volatility patterns have been documented in several markets (see, for example, Jordan et al. (1988) for soybean futures and Ekman (1992) as well as Lee and Linn (1994) for S\&P 500 futures). Daigler (1997) takes advantage of the fact that futures market trading hours are longer than those of cash markets to investigate the Admati and Pfleiderer (1988) and Brock and Kleidon (1992) intraday volatility pattern theories using S\&P 500, Eurodollar, and Treasury Bond Futures. However, at the time his study was conducted, futures trading hours were not much longer than those of the cash market. ${ }^{1}$ He finds that the U-shaped volatility pattern is present in the data, but that for S\&P 500 and Eurodollar futures, volatility decreases before the close of the cash market. Cyree and Winters (2001) document the presence of a U-shaped pattern in the Fed Funds (cash) market. Batten and Lucey (2010) also observe such a U-shaped intraday volatility pattern in the gold futures market; however, their analysis is restricted to trading hours between 8:20 and 15:30 US Eastern time. ${ }^{2}$ Zwergel and Heiden (2012) analyze intraday volatility patterns for DAX futures that are traded from 8:00 to 22:00 central European time, i.e., covering both European and US main market hours. They find a W-shaped volatility pattern, with a first burst of volatility at the open of European stock markets, a second one at the open of US stock markets, and a third one at the close of US markets. Their results also reveal short volatility spikes at the open of futures trading and at the time of US macroeconomic announcements.

Studies seeking to investigate price discovery around the clock have generally had to use cross-listed securities or currencies. Papers using cross-listed securities include Neumark,

\footnotetext{
${ }^{1}$ In 1988 and 1989, the S\&P 500 futures opened at the same time as the cash market but closed 15 minutes later, the Eurodollar futures opened 15 minutes before the cash market and closed at the same time as the S\&P 500 futures, while the Treasury Bond futures traded from 8:20 to 15:00 US Eastern time and then reopened for a night session lasting from 18:00 to 21:30.

${ }^{2}$ At the time of their study, 8:20 to 13:30 were main market hours and available extended hours were from 13:30 to 15:30.
} 
Tinsley, and Tosini (1991), Craig, Dravid, and Richardson (1995) as well as Werner and Kleidon (1996). Andersen and Bollerslev (1998) is one of the few studies providing a characterization of intraday volatility patterns around the clock. Analyzing Deutsche Mark-Dollar foreign exchange quotes, they document pronounced intraday volatility patterns. Volatility is subdued during Pacific hours, picks up at the time of the Tokyo market open, increases again during European trading hours until about 16:00 central European time, then declines monotonically towards the level associated with Pacific hours. Interestingly, they find no signs of elevated volatility when trading closes in New York. Barclay and Hendershott (2003) use the extension of trading hours brought by by the emergence of electronic communications networks to investigate price discovery for Nasdaq stocks during the preopen (8:00 to 9:30 US Eastern time) and the postclose (16:00 to 18:30). They find that although after-hours trading volume is relatively low, it generates significant price discovery, but that prices after hours are noisier, implying that price discovery is less efficient. Breedon and Ronaldo (2013) analyze aggregated hourly trading data on the most important currency crosses and document a significant tendency of both a depreciation as well as more seller- than buyerinitiated trades of the base currency during local trading hours. They conclude that local market participants tend to be net purchasers of foreign currencies.

A large literature relates interday and intraday volatility patterns to macroeconomic announcements. Harvey and Huang (1992) find no U-shaped pattern in foreign exchange futures volatilities during US trading hours (which were from about 7:30 to 13:30 US Central time in their sample). Intraday volatility is hump-shaped on Mondays through Wednesdays, while on Thursdays and Fridays, volatility is highest during the first hour of trading. The authors explain this by the fact that the most important macroeconomic announcements take place during the opening hour of trading on Thursdays and Fridays. Ederington and Lee (1993) specifically investigate the impact of macroeconomic announcements and find that they are responsible for most of the time-of-day and day-of-the-week volatility patterns for the Treasury Bond, Eurodollar, and Deutsche Mark futures. Moreover, after controlling for these announcements, volatility is basically flat both across the trading day and across the trading week. ${ }^{3}$ Christie-David, Chaudhry, and Koch (2000) consider the responses of 15-minute prices of gold and silver futures to monthly US macroeconomic news. While macroeconomic news overall affect metal prices less than interest rates, gold and silver fu-

\footnotetext{
${ }^{3}$ At the time their study was conducted, however, trading hours for the futures contracts they investigate were only from 8:20 to 15:00.
} 
tures both respond strongly to Capacity Utilization and Unemployment Rate news releases. Almeida, Goodhart, and Payne (1998) investigate the reaction of the DEM/USD exchange rate to both US and German macroeconomic news at the five-minute frequency. They provide evidence that the exchange rate quickly and significantly reacts to unexpected news and that its reaction generally reflects anticipated policy responses by monetary authorities. They also find German announcements to have a smaller impact on the exchange rate and to be incorporated more slowly into prices than US ones. Evans and Lyons (2008) consider DEM/USD returns both at the five-minute and daily frequency and find the arrival of broad macroeconomic news to account for over $30 \%$ of total daily price variance. Importantly, they show that the indirect order flow effect - the effect attributable to an increase in the order flow subsequent to the news release - turns out to be about twice as large as the direct news effect.

Another strand of the literature is concerned with cross-market information transmission, both across countries and across different markets within the same country. Lin, Engle, and Ito (1994) investigate the transmission of stock returns and volatility across country indices (specifically the S\&P 500 and the Nikkei), while Engle, Ito, and Lin (1996) consider the transmission of volatility in the Yen/Dollar exchange rate across markets. Booth et al. (1997) investigate the transmission of intraday volatility between the S\&P 500, FTSE 100, and Nikkei 225 futures. They find evidence that volatilities of S\&P 500 and FTSE 100 futures significantly react to information from other markets, whereas the volatility shocks of Nikkei 225 futures are mainly country-specific. Fleming, Kirby, and Ostdiek (1998) estimate correlation coefficients of bivariate $\mathrm{AR}(1)$ volatility processes of daily returns on S\&P 500 index futures, T-bond futures, and T-bill futures and find strong volatility linkages, which they partially attribute to cross-hedging spillovers. Booth and So (2003) investigate intraday information transmission between the German DAX index, futures, and options and document volatility spillover effects for all three markets. Analyzing the VIX and five European implied volatility indices at a daily frequency, Jiang, Konstantinidi, and Skiadopoulos (2012) provide evidence of mutual volatility spillovers and find implied volatilities to drop (rise) on days with scheduled (unscheduled) news events.

A number of papers relate return and volatility linkages across markets to macroeconomic announcements. Becker, Finnerty, and Friedman (1995) analyze 30-minute returns of both 
S\&P 500 and FTSE 100 futures during main market hours. ${ }^{4}$ Focusing on the most important macroeconomic announcements in both countries, both markets appear to respond similarly but independently to US news. However, while FTSE prices react to UK news, the S\&P 500 ignores them. Their finding that international stock markets respond to US information but US markets ignore foreign news suggests that US returns lead foreign prices. Andersen et al. (2007) analyze five-minute returns on futures across different countries and asset classes (S\&P 500, FTSE 100, Euro Stoxx 50, 30-Year-Treasury Bond, British Long Gilt, German Euro Bobl, USD/GBP, USD/JPY, and USD/EUR) around essentially all US macroeconomic news announcements. However, their analysis focuses on open auction regular trading hours and does not include after hours trading. In general, they observe very quick price discovery, i.e., the price response to macroeconomic news occurs within the first five minutes after the actual announcement. Furthermore, many of the US macroeconomic fundamentals also significantly impact foreign bond markets, and in the same direction. Finally, using return spillover regressions, they provide empirical evidence of international stock market crosscorrelations (not only from the US to Europe but also vice versa) even when controlling for the effect of US macroeconomic news releases.

\section{Sample and Data}

Since futures contracts exist on a wide range of assets, the number of contracts that could be investigated is very large. Our analysis focuses on 13 contracts from the main asset classes, namely equities, bonds, currencies, and commodities; for the latter we focus on oil and metals. Specifically, we consider the E-Mini S\&P 500 (ES), Nikkei (NK), and EuroStoxx 50 (XX) equity index futures; the 10-year US Treasury Note (TY), 10-year German Bund (BN), and 10-year Japanese Bond (JB) futures; the EUR/USD (EC) and JPY/USD (JY) currency futures; West Texas Intermediate (CL) and Brent (CO) oil futures; as well as gold (GC), silver (SV), and high-grade copper (HG) futures. All these contracts are widely regarded as global benchmarks and are very liquid, with the daily volume in the front-month contract alone generally exceeding 100,000 contracts.

We obtain five-minute data on these contracts from TickData for the period from April 10, 2010 (the beginning of around-the-clock trading for the Nikkei futures) to August 30,

\footnotetext{
${ }^{4}$ At the time of their study, main market hours were from 9:30 to 16:15 US Eastern time for the S\&P 500 and from 09:35 to 17:10 central European time for the FTSE 100.
} 
2013. Our choice of a five-minute frequency balances our aim of obtaining a precise picture of price behavior around specific times such as the opening of trading on the cash market and the time of scheduled news releases, while avoiding distortions caused by microstructure noise.

For each instrument, we use the front-month contract as it is generally the most liquid. We rollover to the first back-month contract when the latter becomes more liquid. This usually occurs about a week before the front-month contract's last trading date, with the exception of metals, which exhibit a number of peculiarities. For gold, although contracts exist for each calendar month, only the February, April, June, August, October, and December contracts (G, J, M, Q, V, and Z) are liquid at some point during their lifetime. Moreover, trading volume in the front-month contract declines sharply before the first notice date, which is about one month before the last trade date. Therefore, we only make use of data for these six expiration months and perform the contract rollover 35 calendar days prior to expiration. Similarly, for copper and silver, only the March, May, July, September, and December contracts (H, K, N, U, and Z) are liquid at some point during their lifetime, and volume also declines sharply before the first notice date, which is again about one month before the last trade date. Hence, we only consider data for these five expiration months and perform the contract rollover 35 calendar days prior to expiration. For equity index, bond, and currency futures, contracts mature on the March quarterly cycle (H, M, U, and Z), while oil contracts mature each calendar month.

Trading hours for the different instruments and their trading volume are summarized in Table 1. For those contracts that have trading pits, we also report pit trading hours since they will turn out to be important when interpreting our results. For comparability, we convert all times to central European time (CET). As is apparent in Table 1, CET is the most natural time zone to use in our setting since when expressed in CET, trading in all contracts ends before midnight and reopens either at midnight or in early morning hours. Moreover, cash markets for most instruments are closed at midnight CET, i.e., when we switch from one day to the next. Using US Eastern time, for example, would cause us to switch from one trading day to the next when Japanese cash bond and equity markets are open, while using Japanese time would mean switching trade dates while cash markets in Europe and the US are open. Some care must be used in order to deal with daylight savings time (DST). While both the US and Europe have DST, Japan does not. Furthermore, the 
DST switch dates in Europe and the US often differ, with US DST generally starting earlier and finishing later in the year. In order not to introduce additional noise in our results, we delete days where the US has DST but Europe does not from the sample, which eliminates about four weeks of data each year. We adjust for DST when converting Japanese trade times and dates to CET.

As can be seen in Table 1, most contracts in our sample are traded almost around the clock, with nine of the 13 contracts (namely ES, NK, TY, EC, JY, CL, GC, SV, and $\mathrm{HG}$ ) trading 23 hours a day or more. Brent Oil (CO) is traded 22 hours a day, while the EuroStoxx (XX) and Bund (BN) futures are traded 14 hours per day. Accounting for two trading halts of 28 minutes each, Japanese Bond futures (JB) have the shortest trading hours; nevertheless, this contract trades 13 hours and 44 minutes per day. Trading volume in the different contracts is quite large, and ranges from about 10'000 contracts for the Nikkei futures to almost two million contracts for the S\&P 500 E-Mini future (ES). Average volume per five-minute interval ranges from 35 contracts for the Nikkei to almost 7'000 contracts for ES. Moreover, with the exception of the Nikkei and Japanese Bond futures, trading occurs throughout the day, with the share of five-minute intervals with zero trading volume at most a couple of percentage points.

Table 2 reports the distribution of daily volume during the trading day. We divide the trading day into eight periods constructed based on cash market trading hours and the timing of macroeconomic announcements in the different regions as follows (all times are in CET):

1. 00:00-01:00, when all cash markets except currencies are closed but several futures contracts are trading and most Japanese macroeconomic news announcements are released;

2. 01:00-08:00, corresponding to Japanese main market hours;

3. 08:00-09:00, corresponding to European pre-market trading, where Eurex futures are trading but European cash markets are closed;

4. 09:00-13:00, when European cash markets are open, most European macroeconomic announcements are made, but no US macroeconomic news announcements occur;

5. 13:00-15:30, when European cash markets are open, US cash markets are closed, and 
most US macroeconomic news announcements take place $;^{5}$

6. 15:30-17:30, when both European and US cash markets are open and a few US macroeconomic news announcements are released ${ }^{6}$

7. 17:30-22:00, when European cash markets are closed, US cash markets are open, and US Federal Reserve announcements occur;

8. 22:00-00:00, when all cash markets except currencies are closed but several futures contracts are trading.

The results in Table 2 reveal sizable trading volume outside of the trading hours of the instruments' main cash markets. For example, about $25 \%$ of S\&P 500 futures trading volume is transacted outside of the periods when US stock exchanges are open. Similarly, over 30\% of Brent trading volume is observed after the close of European markets. The lowest share of volume outside of main market hours is observed for Japanese government bonds, for which over 85\% of volume is transacted between 01:00 and 08:00 CET. While the share of volume transacted during Asian hours is quite small for oil, it is sizable for metals.

Throughout our analysis, we use log-returns to ensure time additivity. At the beginning of each trading day and following each trading halt, we compute the return from the previous close to the open and record it as the return for the previous five-minute interval (whose endpoint matches the time of the opening of trading). ${ }^{7}$ The return for the first five-minute interval of the trading day and following each trading halt is computed as the open-to-close return during that interval. Finally, the returns for all subsequent five-minute intervals until the close or the next trading halt are computed as the logarithm of the ratio of the closing price in that interval to the closing price in the previous interval in which the instrument traded. Using this approach guarantees a complete set of returns - one for each period in which the instrument traded - whose sum over our sample period equals the return of a long position in the front-month futures that was systematically rolled over before maturity.

\footnotetext{
${ }^{5}$ The pre-market period for the US starts at $13.00 \mathrm{CET}$, which is the time of the first US macroeconomic news announcements (i.e., MBA Mortgage Applications).

${ }^{6}$ For example, ISM, leading indicators and consumer confidence are released at 16:00; see Table 6 for details.

${ }^{7}$ Two contracts in our sample have intraday trading halts: the S\&P 500 E-Mini futures (from 22:15 to 22:30 CET) and Japanese government bond futures (from 3.02/4.02 to 4.30/5.30 CET and from 7.02/8.02 to $7.30 / 8.30 \mathrm{CET}$ in winter/summer).
} 


\section{Price and Variance Contribution during the Day}

As is custom in the literature, we use price contribution to measure the amount of information incorporated into prices during a given time period. Price contribution reflects the fraction of the daily return that has occurred during a given period, i.e.,

$$
P C_{i}=\frac{r_{i}}{r}
$$

where $r_{i}$ denotes the return during period $i$ and $r$ the total return for the day (from the close of after hours trading on the previous day to the close of after hours trading on the current day). Since we use log-returns, price contribution sums to unity on each day. As recommended in Barclay and Hendershott (2003), we calculate the mean price contribution of each interval across days and use its time-series standard error for statistical inference.

Table 3 reports price contribution for the different assets during the eight periods defined in Section 3; periods where an instrument is not traded are marked with dashes. The results in Table 3 reveal sizable price discovery for most instruments outside of their cash market trading hours. For example, over half of both S\&P 500 and EuroStoxx 50 and almost half of Nikkei returns accrue while their respective cash markets are closed. Although price discovery outside of main hours is somewhat smaller for bonds, it remains sizable perhaps with the exception of Japanese bonds. Interestingly, WTI oil exhibits significant price discovery during European trading hours, and Brent oil significant price discovery during US trading hours.

We know from Tables 2 and 3 that both volume and price contribution are sizable outside of main market hours. This raises the natural question of how much price discovery is achieved relative to volume during the different periods of the trading day. To answer this question, we compute the ratio of price contribution relative to the share of daily volume transacted in each period; we call this measure the volume-weighted price contribution

$$
V W P C_{i}=\frac{r_{i} / r}{V_{i} / V}
$$

where $V_{i}$ denotes trading volume during period $i$ and $V$ total daily volume. As was the case for price contribution, volume-weighted price contribution is calculated for each day 
and then averaged across days. ${ }^{8}$ Barclay and Hendershott (2003) perform a similar analysis on their data, but scaling price contribution by the number of trades instead of volume. If trading volume were equally informative at different times of the day, the volume-weighted price contribution would be unity for all periods.

The results in Table 4 reveal that this is by far not the case. While consistent patterns are difficult to identify, it is clearly apparent that many instruments have sizable price contribution per unit of volume outside of their main trading hours. For example, the S\&P 500 has large price contribution during European hours, the EuroStoxx during European pre-market trading, and the Nikkei during Japanese pre-market hours. US and Japanese bonds have high price contribution during the US pre-market period. The Euro has large price contribution during Asian and European pre-market trading. Brent oil has high price contribution during Japanese main hours and the US pre-market period, while WTI oil has high price contribution during European main hours.

An analysis similar to that of price contribution can be performed for variance. For each day, we compute the variance contribution as the sum of the squared returns across all five-minute intervals falling in a given period (plus the squared open return if the market opened at the beginning or during the period in question) divided by the sum of all squared returns for the day. In a second step, we calculate the mean variance contribution of each period across days. As was the case for price contribution, this definition ensures that the sum of the variance contributions of the different periods sum to unity. The results are reported in Table 5. They once again reveal substantial return variation outside of most instruments' main trading hours. To take a few extreme examples, almost $50 \%$ of S\&P 500 return variance and about $60 \%$ of Nikkei return variance occur outside of the trading hours of their respective cash markets. Although they are somewhat more variable when both European and US markets are open, metal prices exhibit sizable variability throughout the day.

Figure 1 reports cumulative price and variance contribution during the day for all instruments grouped by market segment. Four key observations can be made. First, sizable price discovery takes place around the clock for almost all assets. Second, the patterns of price and variance contribution are quite different across assets. Third, price discovery patterns for equities and bonds from the same region are very similar. Finally, for most assets, price

\footnotetext{
${ }^{8}$ Note that since $r_{i}$ can be both positive and negative, differences in weighting between price contribution and volume-weighted price contribution can result in sample averages with opposite signs.
} 
and variance contribution appear to move broadly in line. Put differently, it is not the case that risk and return mainly accrue at different times during the trading day.

Taking a closer look at the price contributions for the different assets reveals some intuitive patterns and some surprising ones. As one would expect, a large part of price contribution for the Nikkei and Japanese government bonds and, to a lesser extent, for the Yen are realized during Japanese trading hours. Also consistent with intuition, price discovery happens earlier in the day for the Yen than for the Euro; for both currencies, however, price discovery is essentially complete by the close of European markets. Interestingly, price discovery also happens earlier for Brent oil than for WTI oil, in spite of the fact that the two are close substitutes. It is noteworthy that price contribution for Brent oil is virtually zero and that for WTI oil is negative but insignificant until European markets open. Here again, price discovery is essentially completed by the close of European markets. More surprisingly, price contribution for the S\&P 500 is virtually zero until European markets open. The same holds for gold and copper, although China and India are the two largest consumers of gold and the former is the largest consumer of copper. Strikingly, price contribution is sizable for silver during Asian market hours, even though the distribution of consumption across continents is quite similar to that for gold, with India, China, and Japan together accounting for over $35 \%$ of world consumption.

As mentioned above, price and variance contribution appear to move broadly in line during the day for most instruments. To substantiate this observation, Figure 2 reports the difference between price and variance contribution for the asset in each category for which this difference is largest, as well as $90 \%$ confidence bounds computed from the empirical distribution of the difference in the sample. It is apparent that the difference between price and variance contribution is generally not statistically different from zero. However, interestingly enough, Figure 2 does provide evidence of some persistent deviations between the two. For both the S\&P 500 (during most of US main hours) and WTI Oil (almost until US pre-market hours) variance contribution appears to lead price contribution, while the opposite holds for the Yen (during most of European main hours) and silver (until US pre-market hours). 


\section{Efficiency of Price Discovery}

In order to assess the efficiency of price discovery, we estimate so-called unbiasedness regressions for each time period $i$ during the day,

$$
r=\alpha_{i}+\beta_{i} r_{c i}+\epsilon_{i}
$$

where $r$ is the total return for the day (from the close of after-hours trading on the previous day to the close of after-hours trading on the current day) and $r_{c i}$ the return from the close of after-hours trading on the previous day to the end of period $i$ on the current day. Such regressions have previously been used by Biais, Hillion, and Spatt (1999) as well as Barclay and Hendershott (2003), who show that if the true return process is serially uncorrelated, the slope coefficient from the unbiasedness regression is equal to the ratio of signal to signal plus noise in the return process. Accordingly, estimates of $\beta_{i}$ around one indicate efficient price discovery, while estimates below one indicate noisy price discovery.

In order to measure how the rate of price discovery changes during the day, we also consider the behavior of the regression $R^{2}$ over time. If the amount of price discovery were constant throughout the day, $R^{2}$ would lie on a straight line starting at zero at the time corresponding to the close of the previous day and reaching one at the time of the close of after-hours trading. ${ }^{9}$ Price discovery is stronger (weaker) than average whenever $R^{2}$ is steeper (flatter) than that benchmark straight line.

Two factors will cause the rate of price discovery to vary during the day: (i) variation in the rate at which new information is released, and (ii) variation in the efficiency with which new information is processed. In order to assess the extent to which these two effects drive the intraday $R^{2}$ patterns, we compute the difference between the regression $R^{2}$ for period $i$ and the share of overall daily price variance that accrues up to the end of period $i$, i.e.,

$$
\psi_{i}=R_{i}^{2}-\frac{\operatorname{var}\left(r_{c i}\right)}{\operatorname{var}(r)} .
$$

Positive values imply that price discovery between the previous close and the end of period $i$ exceeds price variability, indicating that price discovery up to that time is relatively efficient. Conversely, negative values indicate lower price discovery than price variability, implying

\footnotetext{
${ }^{9}$ For example, for an instrument closing at 23:15, the line would start at zero at a time of -0.75 and reach one at a time of 23.25 .
} 
inefficient price discovery. If price discovery were equally efficient throughout the day, the slope of $R^{2}$ plotted against time would vary according to the rate at which new information is released, but $\psi_{i}$ would be zero throughout. Summarizing, plotting $\beta_{i}$ against time informs us about the average ratio of signal to signal plus noise from the previous close to the end of period $i$, plotting $R_{i}^{2}$ against time reveals what share of overall daily price discovery occurs up to the end of period $i$, and plotting $\psi_{i}$ against time indicates whether the share of accrued price discovery taking place up to the end of period $i$ is higher or lower than could be expected based on the corresponding share of accrued daily price variability.

Figure 3 reports the results of this analysis for each of the 13 assets. The upper panels show the slope estimates $\beta_{i}$ from the unbiasedness regressions, their $95 \%$ confidence bounds, and the regression $R^{2} \mathrm{~s}$, while the lower panels report the differences between $R^{2}$ and the share of accrued variance, $\psi_{i}$. Almost all slope coefficients are statistically different from zero and most are not statistically different from unity, indicating that price discovery takes place and is quite efficient around the clock. There are a few noteworthy exceptions, most of which lie during Asian market hours. For example, Japanese government bond price discovery (Panel (d)) is noisy around 2:00, as is Yen price discovery (Panel $(\mathrm{g})$ ) until the beginning of Japanese main market hours. Price discovery is also noisy for US Treasuries, the Euro, gold, silver, and WTI oil (Panels (f), (h), (i), (j), and (l)) during the first two to five hours of trading. Thus, while there is evidence of some inefficiency at specific times, price discovery appears fairly efficient around the clock.

Considering the $R^{2}$ patterns shown in the upper panel for each instrument reveals a number of interesting facts. First, most $R^{2}$ curves are far from linear. Second, the curves are increasing almost everywhere, confirming that price discovery occurs around the clock. There are a couple of essentially flat segments indicating a low rate of price discovery at some times. Most of these segments appear during Asian pre-market hours, the first few hours of Asian trading or after US main market hours. Third, as one would expect, the $R^{2}$ curves are generally steeper during an instrument's main market hours. For example, $R^{2}$ is steeper during Japanese market hours for the Nikkei (Panel (a)), during European hours for the EuroStoxx (Panel (b)), and during US exchange hours for the S\&P 500 (Panel (c)). A similar picture emerges for the three bond markets (Panels (d)-(f)). Fourth, for European assets (EuroStoxx, Bund, and the Euro, see Panels (b), (e), and (h)), the rate of price discovery is highest when both European and US main markets are open. Fifth, the 
distribution of price discovery during the day differs across metals (Panels (i)-(k)): while silver price discovery is very low during Asian hours, price discovery for copper is quite high, with gold lying somewhere in-between. Finally, there is very little price discovery for both oil contracts (Panels (l) and (m)) until the open of European markets, at which point price discovery accelerates. The rate of price discovery then increases again once US markets open, but the increase is more pronounced for WTI than for Brent. Here again, the rate of price discovery is highest when both European and US markets are open.

The lower panels of Figure 3 reveal large differences across assets in the efficiency of price discovery during the day. Overall, efficiency tends to be largest during an instrument's main market hours. For example, for the Nikkei, efficiency is high during Japanese hours, fair during European hours, but low during US hours. For the EuroStoxx, efficiency is highest when both European and US markets are open. By contrast, for the S\&P 500, efficiency is low in early Asian hours, increases during European hours, and is highest during US main market hours. For Japanese bonds, efficiency is low during the first couple of hours of trading, then fair, and then drops sharply at the close of Japanese main markets. For the German Bund, efficiency is high during main market hours and declines around the close of European markets. For US Treasuries, efficiency is low until the release of US macroeconomic news at 14:30 and increases substantially afterwards, before dropping sharply at the close of pit trading at 21:00. Efficiency is quite erratic during the day for the Yen, but exhibits a clear pattern for the Euro: low efficiency until the early afternoon, high efficiency after the release of US macroeconomic news, decreasing efficiency towards the close of European markets, and increasing efficiency during afternoon US trading. All three metals have low efficiency for the first three to four hours of trading. Gold and silver have high efficiency mostly during US hours, but copper also exhibits a period of high efficiency during late Asian hours. For all metals, efficiency drops sharply between the close of Asian markets and the open of European ones. Finally, both oil contracts have low efficiency until about 11:00 and high efficiency afterwards, while for Brent it declines earlier in the evening than for WTI.

Summarizing, the results in this section reveal that there is substantial price discovery around the clock for most assets and that it is quite efficient most of the time. Nevertheless, efficiency tends to be larger during an instrument's main market hours. For most instruments, inefficiency is concentrated before the open of Asian markets or during the first few hours of trading on Asian markets. 


\section{Intraday Volatility Patterns}

Figure 4 shows the average return volatility of the different instruments for each five-minute interval during the trading day, computed as the square root of the average squared return during each interval. While all instruments exhibit strong intraday volatility patterns, the precise shapes of these patterns vary substantially. Strikingly, most assets do not exhibit the U-shaped intraday volatility pattern that has been widely documented for US equities, even if only the trading hours of the underlying or pit market are considered. Generally, intraday spikes in volatility occur at four sets of times: (i) at the open or close of the market for the respective instrument, (ii) at the open or close of the pit for the respective instrument, (iii) at the open or close of other markets (both the cash market for the contract's underlying and markets for other assets), and (iv) at the time of macroeconomic news releases. The remainder of this section describes these effects for the different instruments. The role of US macroeconomic announcements will be investigated in detail in Section 7; for the current discussion, it suffices to note that the main news releases occur in three waves, one at 14:30, one at 16:00, and the last one between 20:00 and 20:45 (details will be provided in Table 6).

Considering equities first (see Panel (a)), S\&P 500 volatility is very low during Asian market hours. This is followed by a short rise in volatility at the start of European premarket trading at 8:00 and a substantial increase at the open of European stock markets at 9:00. Afterwards, a U-shaped pattern similar to that documented in the literature during US cash market hours is clearly visible. At the release of US macroeconomic news at 14:30, volatility spikes and declines quickly thereafter. Volatility spikes again at the open of US stock markets at 15:30. During US cash market hours, the above mentioned U-shaped pattern is visible; however, two short spikes in volatility occur at the time of the second and third waves of US macroeconomic releases (16:00 and 20:00-20:45). S\&P 500 volatility then falls sharply around the time of the close of the cash market. For the EuroStoxx, volatility is very high at the open of pre-market trading at 8:00, as the information accumulated during the night gets incorporated into prices. Afterwards volatility is rather low during the rest of pre-market trading and increases sharply at the open of European cash markets at 9:00. It thereafter exhibits a U-shaped pattern before spiking at the time of US macroeconomic news releases at 14:30. While that pattern is quite similar to that for the S\&P 500 during the same period, EuroStoxx volatility is much higher, even at the exact time of US macroeconomic news releases. Volatility then decreases slowly before rising substantially at the open of US 
stock markets at 15:30. It remains elevated and much higher than S\&P 500 volatility until the close of European stock markets at 17:30, and is thereafter virtually equal to S\&P 500 volatility for the rest of the day. Finally, the Nikkei has elevated volatility during Japanese market hours, but no U-shape pattern is apparent during that time. Its volatility declines sharply at the close of Japanese cash markets and, after a brief increase at the beginning of European cash market trading, decreases progressively towards the level of S\&P 500 volatility during European hours. Nikkei volatility then spikes twice, at the time of US macroeconomic news announcements and at the open of US stock markets. During US stock market hours, it is very similar to S\&P 500 volatility, increases substantially towards the close of US stock markets, before declining somewhat towards the close of after-hours trading.

Turning to bonds (see Panel (b)), after initial spikes at the open and at the release of Japanese macroeconomic news shortly thereafter, US Treasury volatility is quite low during Asian trading hours, increases at the open of European pre-market and main market trading, afterwards rises progressively before spiking at the time of US macroeconomic news releases at 14:30. No major increase in volatility occurs at the open of US stock markets at 15:30, but there is a large spike in volatility at the time of the second wave of US macroeconomic news releases at 16:00, followed by one at 19:00 and one at the time of Federal Reserve policy announcements at 20:00. Interestingly, no U-shaped pattern is visible. For German Bunds, the early part of the day exhibits a pattern similar to the EuroStoxx: volatility is very high at the open of pre-market trading when the information accumulated during the night gets incorporated into prices, then falls during the rest of pre-market trading and increases sharply at the open of cash markets at 9:00. It declines thereafter with short increases at 10:00, 10:30, and 11:00, when some European macroeconomic news are released. During this period Bund volatility is much larger than US Treasury volatility. At 14:30, volatility spikes as it does for US Treasuries. Bund volatility exceeds US Treasury volatility until the close of European cash markets and thereafter decreases. The three volatility spikes at 16:00, 19:00, and 20:00 that were observed for Treasuries are also clearly visible for Bunds, but are somewhat smaller. Finally, Japanese bond volatility is largest at the open of Japanese markets, fairly large during Japanese main market hours, especially in the afternoon (4:007:00 CET), declines during European hours and spikes at the time of the 14:30 and 16:00 US macroeconomic news releases.

As can be seen in Panel (c), volatility patterns for currencies are much less smooth than 
for bonds and equities. Overall, the patterns for the Euro and the Yen are quite similar; the main difference between the two is that - as one could expect - Yen volatility exceeds Euro volatility during Asian hours and Euro volatility exceeds Yen volatility during European hours. Put differently, Yen volatility is similar during Asian and European hours, while Euro volatility is much higher during European hours than during Asian hours. Both Euro and Yen volatility spike at the time of the 14:30 and 16:00 US macroeconomic news releases. After the close of European markets, Yen and Euro volatility remain pretty similar.

Turning to oil (see Panel (d)), Brent volatility exceeds WTI volatility in early trading; there is a spike in Brent volatility at 2:00, corresponding to the open of Brent futures trading on weekdays. Afterwards, the volatility of both contracts is quite similar until US markets open, hovering at low levels during Asian hours, increasing sharply when European markets open, and spiking at the time of the 14:30 macroeconomic announcements. Once US markets open, WTI volatility exceeds Brent volatility. There are numerous spikes during US trading hours: one at the open of the WTI futures pit at 15:00, one at the open of US stock markets at 15:30, one at the time of the second wave of macroeconomic releases at 16:00, one at the time of the release of US oil inventory data at 16:30, and one at the close of the WTI futures pit at 20:30. After 20:30, oil volatility declines substantially and remains rather low until the end of the day.

Panel (e) reveals that metals exhibit the most erratic intraday volatility patterns across all asset classes. Out of the three metals, gold is the least and silver the most volatile. The volatility patterns for both are quite similar: large volatility at the open, spikes at the open of Japanese cash markets, an increase in the volatility level until the open of European markets, and large spikes at the time of the 14:30 and 16:00 US macroeconomic news releases. There are also substantial volatility spikes at 19:25 for silver and 19:30 for gold, which correspond to the close of pit trading for these two metals. Volatility then declines before increasing at the time of the Federal Reserve announcements at 20:00; thereafter it decreases before spiking again at the close of US stock markets at 22:00 and drops sharply afterwards. Finally, copper volatility spikes at the open, decreases thereafter before spiking again at the open of Japanese cash markets, then declines until the open of European cash markets. It spikes at the time of US macroeconomic announcements, remains fairly elevated until the close of European markets, falls thereafter before spiking twice - once at 19:00, the close of pit trading for copper, and once at 20:00, the time of Federal Reserve announcements. Overall, 
copper volatility differs somewhat less between the main trading hours of the different regions than gold and silver volatility.

\section{Diffusion and Jump Risk During the Trading Day}

The sharp spikes in intraday volatility documented in Section 6 are consistent with the strong empirical evidence for the presence of both diffusion and jump components in asset returns (see, e.g., Chernov et al. (2003), Eraker (2004), Broadie et al. (2007), Ait-Sahalia and Jacod (2009), Lahaye et al. (2011), and the references therein). In this section, we aim to disentangle the two for every five-minute interval of the trading day. This is a nontrivial task since when considering individual high frequency returns, there is no guarantee that standard measures of diffusion risk are actually bounded by total return variance. We propose the following procedure in order to mitigate this issue.

Our starting point is the fact that the total variance $T V$ of any given five-minute return $r_{i}$ is the sum of its diffusion component $D V$ and jump component $J V$, i.e.,

$$
T V_{i}=D V_{i}+J V_{i}
$$

To estimate the diffusion component, we use the jump-robust integrated variance estimator MedRV proposed by Andersen, Dobrev, and Schaumburg (2007). Formally, our estimator of the diffusion component of total variance during interval $i$ is

$$
D V_{i}=\frac{\pi}{6-4 \sqrt{3}+\pi} \operatorname{med}\left(\left|r_{i-1}\right|,\left|r_{i}\right|,\left|r_{i+1}\right|\right)^{2}
$$

where "med" denotes the median and the scaling factor ensures the unbiasedness of $D V$ as an estimator of spot variance if returns are i.i.d. Gaussian.

Each day, for each five-minute interval $i$, we use Lee and Mykland's (2008) jump detection test to assess the likelihood that a jump in the return process has occurred during that interval. The test statistic proposed by Lee and Mykland (2008) is given by

$$
\mathcal{L}_{i} \equiv \frac{r_{i}}{\widehat{\sigma}_{i}}
$$

where $\widehat{\sigma}_{i}$ denotes the estimate of the underlying price process' instantaneous volatility. In- 
tuitively, the larger the absolute value of $\mathcal{L}_{i}$ (i.e., the absolute size of the return $r_{i}$ relative to the current volatility estimate) during interval $i$ on a given trading day, the higher the probability that a jump occurred during that interval. To be consistent with our definition of $D V$, we again rely on the jump-robust $M e d R V$ to estimate instantaneous volatility in $(7)$, i.e., we estimate $\widehat{\sigma}_{i}$ using

$$
\widehat{\sigma}_{i}=\frac{1}{K-2} \sum_{j=i-K+1}^{i-2} \frac{\pi}{6-4 \sqrt{3}+\pi} \operatorname{med}\left(\left|r_{j-1}\right|,\left|r_{j}\right|,\left|r_{j+1}\right|\right)^{2}
$$

where $K$ denotes the window size.

Following Lee and Mykland (2008), we then compute the centered test statistic

$$
\frac{\left|\mathcal{L}_{i}\right|-C_{n}}{S_{n}}
$$

where

$$
C_{n}=\frac{\sqrt{2 \ln n}}{c}-\frac{\ln \pi+\ln (\ln n)}{2 c \sqrt{2 \ln n}}, \quad S_{n}=\frac{1}{c \sqrt{2 \ln n}}, \quad c=\sqrt{\frac{2}{\pi}},
$$

and $n$ denotes the number of observations per day. The null hypothesis of no jump during interval $i$ is rejected whenever the centered test statistic exceeds the critical value $q_{\alpha}=$ $-\ln (-\ln (\alpha))$, where $\alpha$ corresponds to the test's confidence level. Consistent with Lee and Mykland's (2008) proposed implementation, we choose the window size $K$ equal to 288 (the number of five-minute intervals per day) and set the confidence level to $99.9 \%(\alpha=0.999)$.

Finally, we compute the diffusion and jump components $D V_{i}$ and $J V_{i}$ using the following decomposition algorithm:

1. For each five-minute return $r_{i}$, compute the corresponding centered test statistic $\frac{\left|\mathcal{L}_{i}\right|-C_{n}}{S_{n}}$ in order to determine whether a jump has occurred during interval $i$.

2. If no jump has occurred during interval $i$, then $J V_{i}=0$ and $T V_{i}=D V_{i}$.

3. If a jump has occurred during interval $i$, then $J V_{i}=\max \left\{r_{i}^{2}-D V_{i}, 0\right\}$ and $T V_{i}=$ $D V_{i}+J V_{i}$

Although this procedure imposes the non-negativity of $J V$, the constraint will only be binding if $\frac{\left|\mathcal{L}_{i}\right|-C_{n}}{S_{n}}>q_{0.999}$ and either (i) $\left|r_{i}\right|$ is the median or the smallest absolute return in (6) or (ii) $\left|r_{i}\right|$ is the largest absolute return in (6) but at least one of $\left|r_{i-1}\right|$ and $\left|r_{i+1}\right|$ is greater 
than $\left|r_{i}\right|$ divided by the scaling factor in (6). Essentially, a binding non-negativity constraint requires the presence of at least one additional jump in the immediately adjacent intervals. ${ }^{10}$ When we relax the above non-negativity constraint, only six average jump components are below -0.0005 across all intervals and contracts (of which there are over 3,000 in total). ${ }^{11}$ The results presented below are not affected by the non-negativity restriction on $J V$.

Figure 5 presents the average total variance $T V$ and its diffusion and jump components $D V$ and $J V$ during the trading day for all 13 contracts. For three contracts (EuroStoxx, Bund, and Brent oil) we report the value for the opening interval instead of its corresponding data point in order to enhance visibility. The results in Figure 5 clearly demonstrate that both diffusion and jump variance components are important drivers of overall intraday variance patterns.

Considering first the diffusion component, intraday variance patterns for the three equity indices are rather different (see Panels (a)-(c)). In general, most diffusive price fluctuations occur during the main trading hours of the respective underlying asset, but Nikkei volatility increases when US stock markets are open. The well-documented U-shape of S\&P 500 intraday volatility during US main market hours is strikingly clear once the jump component is removed from total variance. The U-shapes for the EuroStoxx, however, are much less pronounced. Confirming the findings in Section 6, none of the other assets has a U-shaped intraday volatility pattern, even when only considering diffusive risk. The results in Figure 5 also reveal that once the effect of jumps is removed, gold and silver variances appear strikingly similar, as do those of WTI and Brent oil (see Panels (i)-(j) and (l)-(m), respectively).

Turning to the jump component, the three main release times of US macroeconomic news (14:30, 16:00, and 20:00-20:45) are strikingly visible for all three equity indices. For the Bund, US Treasury bonds, the Yen, and gold, the 14:30 macroeconomic announcements account for the bulk of jump risk. By contrast, both oil contracts, copper, and to a lesser extent silver exhibit sizable jumps at numerous times during the day. Both oil contracts have strikingly similar jump variance patterns.

Finally, we provide a quantitative assessment of the variance contribution of jumps associated with US macroeconomic announcements. In contrast to most previous studies, our aim

\footnotetext{
${ }^{10}$ For case (i) to occur, there must be at least one additional, larger jump in an adjacent interval. For case (ii) to occur, the size of the return in at least one of the adjacent intervals must be over $\frac{6-4 \sqrt{3}+\pi}{\pi}=70.45 \%$ of the size of the return in interval $i$, implying a second jump or extremely high diffusion volatility in an adjacent interval.

${ }^{11}$ There are three for NK, one for SV and one each at the open of $\mathrm{CO}$ and XX.
} 
is not to quantify the variance impact of individual announcement types, but to assess their overall relevance for intraday variance patterns. Accordingly, we group the announcements in three groups based on their scheduled release times (14:30, 16:00, and 20:00-20:45). Table 6 provides an overview of all announcements considered in each group, their frequency, source, and scheduled release time in CET. Since the release time of Federal Reserve announcements varies somewhat by announcement type and changed slightly during our sample period, we include all such announcements in the third group; their release times all lie between 20:00 and 20:45 CET.

For each announcement group, Table 7 provides the size rank and contribution to total daily return variance of the jump component for the five-minute interval immediately following the release time. Because of the slight changes in the time of Federal Reserve announcements discussed above, for the third announcement group we report the values for the largest jump between 20:00 and 20:45 as well as the time at which it occurs. The results in Table 7 clearly indicate that for almost all assets, the largest jump occurs right after the first announcements at 14:30 CET, the only exceptions being the Nikkei and both oil contracts. For both oil contracts, the largest jump (not reported in the table) happens at the release of US oil inventory data at 16:30 CET. The largest contributions of the 14:30 announcement jump to total daily variance are observed for US Treasuries (4.77\%), the S\&P 500 (1.69\%), the Bund (1.54\%), and gold (1.22\%). The size of these contributions is remarkable since they represent averages across all trading days and the announcements listed in Table 6 are released monthly or weekly at most. For equities, the second most important announcements are the FOMC press conferences. By contrast, for metals and perhaps surprisingly bonds, the second group of announcements appears to be more likely to cause large jumps.

The right-most column in Table 7 reports the total contribution of jumps to overall daily return variance. The contribution of jumps is important, accounting for approximately $5 \%$ to $13 \%$ of total daily return variance even though most days do not have any announcements. The contribution of jumps is largest for the Yen, US, and Japanese government bonds, as well as for gold and silver.

Summarizing, the results in this section show that the contribution of jumps to overall daily volatility is substantial, that both diffusion and jump components are significant drivers of observed intraday volatility patterns, and that a sizable fraction of jump-driven volatility occurs around US macroeconomic news announcements, which strongly affect all 
assets classes.

\section{The Volume-Volatility Relationship during the Day}

Previous research documents that volatility and trading volume are strongly positively correlated, and a number of theoretical results suggest that one should expect a linear relationship between the two (see Huberman and Stanzl (2004) and the references therein). The standard explanation for the existence of a relationship between volume and volatility is that asymmetric information gets incorporated into prices through trading. As shown in Section 7, however, jumps are mostly associated with the public release of information. This suggests that the relationship between volume and volatility could be very different at the time of jumps.

Figure 6 reports the share of overall trading volume and of price volatility for each fiveminute interval during the day, as well as the difference between the two. While there is clearly strong comovement between volume and volatility, the relationship is far from perfect. Three main observations can be made. First, with the exception of Japanese government bonds, volume is generally significantly higher than volatility during US trading hours. Second, the relationship between volume and volatility that can be observed during most of the day often does not hold at the time of jumps. Specifically, while both volume and volatility spike at the time of jumps, the difference between the two sometimes does and sometimes does not. This suggests that in some - but not all - markets, traders anticipate large moves in the price at the time of scheduled announcements and market depth falls accordingly. Third, the opening and closing of stock markets or futures pits tend to be associated with spikes in trading volume that are much larger than the contemporaneous spikes in volatility. Moreover, these spikes in volume are often substantially greater than those associated with price jumps. We now discuss these effects for the different instruments.

Considering first equities, for the Nikkei (Panel (a)), volume is much smaller than volatility during Japanese main market hours, somewhat greater during European hours, and sizably larger than volatility during US hours. ${ }^{12}$ Volume spikes more strongly than volatility at

\footnotetext{
${ }^{12}$ To some extent, the fact that volume is smaller than volatility during Japanese hours could be caused by the fact that a competing contract with essentially the same specifications is traded on the Osaka stock exchange and is likely to be preferred by Japanese investors. We have chosen to use the CME contract as its trading hours are much longer.
} 
the time of the 14:30 and 16:00 US macroeconomic releases, at the close of European stock markets at 17:30, and at the close of US stock markets at 22:00. For the EuroStoxx (see Panel (b)), volume is considerably lower than volatility during European pre-market trading but exceeds volatility during the first hour after the open of European stock markets. Both volume and volatility are about the same until the open of US stock markets, at which point volume increases more strongly than volatility. Interestingly, the spikes in volume and volatility at the time of the 14:30 US macroeconomic news releases are equally large. Volume spikes at the time of the close of European stock markets at 17:30, but volatility increases only slightly. After the close of European markets, volatility is much higher than volume. No sizable change in volume is apparent at the time of the price jump associated with Federal Reserve announcements around 20:00. For the S\&P 500 (see Panel (c)), volume is lower than volatility until the open of US stock markets, after which it is substantially larger. Volume spikes slightly less than volatility at the time of the jumps associated with 14:30 US macroeconomic news releases and the Federal reserve announcements at 20:00. The opposite is true for the second wave of US macroeconomic announcements at 16:00.

Turning to bonds, the relationship between volume and volatility is quite erratic at the open for Japanese government bonds (see Panel $(\mathrm{d})$ ). Overall, volume is much larger than volatility during Japanese main market hours and lower afterwards. There is a large increase in volume at the close of the main market at 7:00/8:00 (winter/summer), but it is not associated with a commensurate spike in volatility. For the German Bund (see Panel (e)), volume exceeds volatility during European morning hours and from the 14:30 US macroeconomic news releases until the close of European markets at 17:30. Volume spikes more sharply than volatility at the time of the 14:30 price jump. For US Treasuries (see Panel (f)), volume is notably lower than volatility outside of US trading hours. There are two spikes in volume that are larger than those in volatility, one at the open of the pit market at 14:20, and a second at the time of the 14:30 US macroeconomic news releases. The open of US stock markets at 15:30 is associated with a sharp rise in volume but very little movement in volatility. Volume spikes more strongly than volatility when the second wave of US macroeconomic releases is issued at 16:00. Both volume and volatility spike about equally strongly at the time of Federal Reserve announcements at 20:00. Finally, there is a very large spike in volume, but a much smaller increase in volatility right before the close of the pit market at 21:00. 
For currencies, the relationship between volume and volatility is quite similar for the Yen and the Euro (Panels (g) and (h)): volume is lower than volatility during Asian trading hours, about the same during European hours, and much larger between the time of the 14:30 US macroeconomic releases and the close of European stock markets. After the close of the futures pit at 21:00, volume is considerably lower than volatility. Volume spikes more strongly than volatility at the time of the price jumps associated with US macroeconomic announcements, 14:30 and 16:00. The same can be observed before the close of European markets at 17:30. There are also two spikes in volume that are stronger than those in volatility at the open and close of the futures pits, 14:20 and 21:00.

Considering metals (Panels (i)-(k)), trading volume is lower than volatility outside of pit trading hours and higher than volatility during pit trading hours. Volume spikes more strongly than volatility at the open and close of the pits (14:20 and 19:30 for gold, 14:25 and 19:25 for silver, and 14:10 and 19:00 for copper), at the time of the price jumps associated with the 14:30 and 16:00 US macroeconomic releases, and at the open of US stock markets at $15: 30$.

For WTI oil (see Panel (1)), volume is lower than volatility outside of pit hours (15:0020:30) and exceeds it during pit hours. At the open and close of the pit, volume spikes much more strongly than volatility. The same holds at the open of US stock markets, at the time of the 16:00 macroeconomic announcements, and when oil inventory data is released at 16:30. For Brent oil (see Panel (m)), volume is lower than volatility during Asian hours, about the same during European hours, and higher when both European and US markets are open. The largest spikes in volume occur at the close of European stock markets and of the WTI pit. The spikes in volume at the times of the main price jumps - the 14:30 macroeconomic releases, the 16:30 oil inventory releases, and the 20:00 Federal reserve releases - are somewhat, but not much, larger than the associated spikes in volatility.

Overall, two facts about intraday volume-volatility relationships are especially striking. First, the behavior at jump times differs significantly across instruments. To illustrate, at 14:30, the spikes in volume are much larger than those in volatility for some assets - the Nikkei, the Bund, US Treasuries, both currencies and all metals - while they are of about the same magnitude for others - the EuroStoxx, the S\&P 500, and oil. This suggests differences across markets in traders' anticipation of large price moves at the time of scheduled announcements. Second, a number of assets have very large spikes in volume that are not 
associated with commensurate spikes in volatility not just at times when the underlying cash market or futures pit opens or closes, but also when markets for other assets open or close. The most striking examples are the rise in Nikkei volume at the open of US stock markets and that in Brent volume at the close of European stock markets.

\section{Conclusion}

We investigate price discovery around the clock for 13 global benchmark assets from the main asset classes equities, currencies, bonds, and commodities. We document that sizable price discovery occurs around the clock for almost all assets. For a given asset, the distribution of risk and return during the day is fairly similar, indicating a broadly constant risk-returnrelationship during the trading day.

Although the amount of price discovery varies significantly during the day and across assets, price discovery generally is quite efficient around the clock for most assets. Nevertheless, efficiency tends to be higher during an asset's main market hours, and there exist short periods where price discovery is inefficient. For most instruments, inefficiency is concentrated before the open of Asian markets or during the first few hours of trading on Asian markets.

All assets show strong intraday volatility patterns, but the precise shapes of these patterns vary substantially across assets. Strikingly, most assets do not exhibit the U-shaped intraday volatility pattern that has been widely documented for US equities, even if only the trading hours of the underlying or pit market are considered. Intraday spikes in volatility occur at four sets of times: (i) at the open or close of the market for the respective asset, (ii) at the open or close of the futures pit for the respective asset, (iii) at the open or close of other markets (both the underlying cash market and markets for other assets), and (iv) at the time of macroeconomic news releases. Most assets react strongly to US macroeconomic news releases and have higher volatility during US trading hours, but also exhibit strong volatility outside of US trading hours.

The decomposition of intraday volatility into its diffusion and jump components reveals that both diffusion and jump volatility are important drivers of overall intraday volatility patterns. The contribution of jumps to overall volatility is substantial, accounting for approximately $5 \%$ to $13 \%$ of total daily return variance. A sizable fraction of jump-driven 
volatility occurs around US macroeconomic news announcements, which affect all assets in our sample.

In general, volume significantly exceeds volatility during US trading hours. The relationship between volume and volatility that can be observed during most of the day often does not hold at jump times. Both volume and volatility spike at the time of jumps, but the difference between the two sometimes does and sometimes does not. This suggests that in some - but not all - markets, traders anticipate large price moves at the time of scheduled announcements and market depth falls accordingly. The opening and closing of stock markets or futures pits tend to be associated with spikes in trading volume that are much larger than the contemporaneous spikes in volatility. Strikingly, these spikes in volume are often considerably greater than those associated with price jumps. For some assets, such spikes even occur at the open or close of markets for other assets.

Overall, our results highlight the importance of around-the-clock trading for price discovery. Explaining the observed differences in intraday volume and volatility patterns across assets that are traded around the clock is a promising avenue for future research.

\section{References}

Admati, Anat R., and Paul Pfleiderer (1988): "A theory of intraday patterns: Volume and price variability," Review of Financial Studies 1, 3-40.

Ait-Sahalia, Yacine, and Jean Jacod (2009): "Estimating the Degree of Activity of Jumps in High Frequency Data," Annals of Statistics 37, 2202-2244.

Almeida, Alvaro, Charles Goodhart, and Richard Payne (1998): "The Effects of Macroeconomic News on High Frequency Exchange Rate Behavior," Journal of Financial and Quantitative Analysis 33, 383-408.

Andersen, Torben G., and Tim Bollerslev (1998): "Deutsche Mark-Dollar volatility: Intraday activity patterns, macroeconomic announcements, and longer run dependencies," Journal of Finance 53, 219-265.

Andersen, Torben G., Tim Bollerslev, Francis X. Diebold, and Clara Vega (2007): "Realtime price discovery in global stock, bond and foreign exchange markets," Journal of International Economics 73, 251-277. 
Andersen, Torben G., Dobrislav Dobrev, and Ernst Schaumburg (2010): "Jump-Robust Volatility Estimation using Nearest Neighbor Truncation", Federal Reserve Bank of New York Staff Reports 465.

Barclay, Michael J., and Terrence Hendershott (2003): "Price discovery and trading after hours," Review of Financial Studies 16, 1041-1073.

Batten, Jonathan A., and Brian M. Lucey (2010): "Volatility in the gold futures markets," Applied Economics Letters 17, 187-190.

Becker, Kent G., Joseph E. Finnerty, and Joseph Friedman (1995): "Economic news and equity market linkages between the U.S. and U.K.," Journal of Banking and Finance 19, 1191-1210.

Biais, Bruno, Pierre Hillion, and Chester S. Spatt (1999): "Price Discovery and Learning during the Preopening Period in the Paris Bourse," Journal of Political Economy 107, 1218-1248.

Booth, G. Geoffrey, Mustafa Chowdhury, Teppo Martikainen, and Yiuman Tse (1997): "Intraday Volatility in International Stock Index Futures Markets: Meteor Showers or Heat Waves?," Management Science 43, 1564-1576.

Booth, G. Geoffrey, and Raymond W. So (2003): "Intraday volatility spillovers in the German equity index derivatives market," Applied Financial Economics 13, 487-494.

Breedon, Francis, and Angelo Ranaldo (2013): "Intraday Patterns in FX Returns and Order Flow," Journal of Money, Credit and Banking 45, 953-965.

Broadie, Mark, Mikhail Chernov, and Michael Johannes (2007): "Model Specification and Risk Premia: Evidence from Futures Options," Journal of Finance 62, 1453-1490.

Brock, William A., and Allan W. Kleidon (1992): "Periodic market closure and trading volume: A model of intraday bids and asks," Journal of Economic Dynamics and Control $16,451-489$.

Chernov, Mikhail, A. Ronald Gallant, Eric Ghysels, and George Tauchen (2003): "Alternative models for stock price dynamics," Journal of Econometrics 116, 225-257. 
Christie-David, Rohan, Mukesh Chaudhry, and Timothy W. Kock (2000): "Do Macroeconomics News Releases Affect Gold and Silver Prices?," Journal of Economics and Business $52,405-421$.

Craig, Alastair, Ajay Dravid, and Matthew Richardson (1995): "Market efficiency around the clock: Some supporting evidence using foreign-based derivatives," Journal of Financial Economics 39, 161-180.

Cyree, Ken B., and Drew B. Winters (2001): "An intraday examination of the Federal Funds market: Implications for the theories of the reverse-J pattern," Journal of Business 74, $535-556$.

Daigler, Robert T. (1997): "Intraday futures volatility and theories of market behavior," Journal of Futures Markets 17, 45-74.

Ederington, Louis H., and Jae Ha Lee (1993): "How markets process information: News releases and volatility," Journal of Finance 48, 1161-1191.

Ekman, Peter D. (1992): "Intraday patterns in the S\&P 500 index futures market," Journal of Futures Markets 12, 365-382.

Engle, Robert F., Takatoshi Ito, and Wen-Ling Lin (1990): "Meteor showers or heat waves? Heteroskedastic intra-daily volatility in the foreign exchange market," Econometrica 58, $525-542$.

Eraker, Bjorn (2004): "Do stock prices and volatility jump? Reconciling evidence from spot and option prices," Journal of Finance 59, 1367-1404.

Evans, Martin D.D. and Richard K. Lyons (2008): "How is macro news transmitted to exchange rates?," Journal of Financial Economics 88, 26-50.

Fleming, Jeff, Chris Kirby, and Barbara Ostdiek (1998): "Information and volatility linkages in the stock, bond, and money markets," Journal of Financial Economics 49, 111-137.

Harvey, Campbell R. and Roger D. Huang (1991): "Volatility in the foreign currency futures market," Review of Financial Studies 4, 543-569. 
Huberman, Gur and Werner Stanzl (2004): "Price Manipulation and Quasi-Arbitrage," Econometrica 72, 1247-1275.

Jiang, George J., Eirini Konstantinidi, and George Skiadopoulos (2012): "Volatility spillovers and the effect of news announcements," Journal of Banking and Finance 36, 2260-2273.

Jordan, James V., William E. Seale, Stephen J. Dinehart, and David E. Kenyon (1988): "The intraday variability of soybean futures prices: information and trading effects," Review of Futures Markets 7, 96-109.

Lahaye, Jerome, Sebastien Laurent, and Christopher J. Neely (2011): "Jumps, cojumps and macro announcements," Journal of Applied Econometrics 26, 893-921.

Lee, Jae Ha, and Scott C. Linn (1994): "Intraday and overnight volatility of stock index and stock index futures returns," Review of Futures Markets 13, 1-29.

Lee, Suzanne S., and Per A. Mykland (2008): "Jumps in Financial Markets: A New Nonparametric Test and Jump Dynamics," Review of Financial Studies 21, 2535-2563.

Lin, Wen-Ling, Robert F. Engle, and Takatoshi Ito (1994): "Do bulls and bears move across borders? International transmission of stock returns and volatility," Review of Financial Studies 7, 507-538.

Neumark, David, P.A. Tinsley, and Suzanne Tosini (1991): "After-hours stock prices and post-crash hangovers," Journal of Finance 46, 159-178.

Werner, Ingrid M., and Allan W. Kleidon (1996): "U.K. and U.S. trading of British crosslisted stocks: An intraday analysis of market integration," Review of Financial Studies 9, 619-664.

Wood, Robert A., Thomas H. McInish, and J. Keith Ord (1985): "An investigation of transactions data for NYSE stocks," Journal of Finance 40, 723-739.

Zwergel, Bernhard, and Sebastian Heiden (2012): "Intraday futures patterns and volumevolatility relationships: the German evidence," Review of Management Science 40, 723739 . 
Table 1

Trading Hours and Summary Statistics

\begin{tabular}{|c|c|c|c|c|c|c|}
\hline \multirow{2}{*}{ Futures Contract } & \multirow{2}{*}{ Exchange } & \multicolumn{2}{|c|}{ Trading Hours (CET) } & \multicolumn{2}{|c|}{ Average Trading Volume } & \multirow{2}{*}{$\begin{array}{l}\% \text { of empty } 5 \\
\text { Min. Intervals }\end{array}$} \\
\hline & & Electronic & Pit & Per Trading Day & Per 5-Min. Interval & \\
\hline \multicolumn{7}{|l|}{ Equities } \\
\hline S\&P $500(\mathrm{ES})$ & $\mathrm{CME}$ & $00: 00-23: 15$ & - & 1'927'540 & 6'884 & $2.3 \%$ \\
\hline EuroStoxx 50 (XX) & Eurex & 08:00-22:00 & - & 1'062'657 & 6325 & $0.2 \%$ \\
\hline Nikkei (NK) & CME & $00: 00-23: 15$ & - & 9'772 & 35 & $29.9 \%$ \\
\hline \multicolumn{7}{|l|}{ Bonds } \\
\hline 10y US T-Note (TY) & $\mathrm{CBOT}$ & 00:00-23:00 & $14: 20-21: 00$ & 1'024'050 & 3'710 & $2.5 \%$ \\
\hline 10y German Bund (BN) & Eurex & 08:00-22:00 & - & $732 ' 713$ & $4 ' 361$ & $0.2 \%$ \\
\hline 10y Japanese Bond (JB) & OSE & $00: 45-15: 25$ & $00: 45-07: 02$ & $30^{\prime} 938$ & 200 & $24.9 \%$ \\
\hline \multicolumn{7}{|l|}{ Currencies } \\
\hline EUR/USD (EC) & CME & $00: 00-23: 15$ & $14: 20-21: 00$ & $280 ’ 630$ & 1'017 & $0.9 \%$ \\
\hline JPY/USD (JY) & $\mathrm{CME}$ & $00: 00-23: 15$ & $14: 20-21: 00$ & $112^{\prime} 325$ & 407 & $0.9 \%$ \\
\hline \multicolumn{7}{|l|}{ Oil } \\
\hline WTI Oil (CL) & NYMEX & $00: 00-23: 15$ & $15: 00-20: 30$ & $207^{\prime} 072$ & 742 & $0.6 \%$ \\
\hline Brent Oil (CO) & $\mathrm{ICE}$ & 02:00-00:00 & - & $100^{\prime} 599$ & 388 & $6.1 \%$ \\
\hline \multicolumn{7}{|l|}{ Metals } \\
\hline Gold (GC) & NYMEX & $00: 00-23: 15$ & $14: 20-19: 30$ & $101^{\prime} 728$ & 365 & $3.9 \%$ \\
\hline Copper (HG) & NYMEX & $00: 00-23: 15$ & $14: 10-19: 00$ & $36^{\prime} 097$ & 129 & $2.1 \%$ \\
\hline Silver (SV) & NYMEX & $00: 00-23: 15$ & $14: 25-19: 25$ & $39 ' 142$ & 140 & $2.1 \%$ \\
\hline
\end{tabular}

This table provides the total available and pit trading hours (CET) as well as the respective exchanges for all futures contracts in our sample. The sample period is from April 10, 2010 to August 30, 2013. Trading hours for Japanese bond futures (JB) expressed in CET vary between winter and summer since Europe has daylight savings time (DST) but Japan does not. The time entries in the table refer to winter time; during the part of the year where DST is used in Europe, all times for JB expressed in CET are one hour later. For the E-Mini S\&P 500 equity index futures (ES) there exists one trading halt (from 22:15 to 22:30 CET) and for JB there exist two trading halts (from 3:02/4:02 to 4:30/5:30 CET and from 7:02/8:02 to 7:30/8:30 CET in winter/summer, respectively) during our sample period. Trading for Brent oil futures (CO) starts at 02:00 on weekdays; however, on Sundays trading already opens at midnight. The fifth and sixth columns report the average daily trading volume and the average trading volume per five-minute interval (considering only five-minute intervals that fall within trading hours), respectively. The last column reports the percentage of five-minute intervals during trading hours with zero trading volume. 
Table 2

Distribution of Volume during the Trading Day

\begin{tabular}{|c|c|c|c|c|c|c|c|c|}
\hline \multirow{4}{*}{ Futures Contract } & \multirow{2}{*}{\multicolumn{2}{|c|}{ Japan }} & \multirow{2}{*}{\multicolumn{2}{|c|}{ Europe }} & \multicolumn{2}{|c|}{ Europe \& US } & \multirow{3}{*}{$\frac{\text { US }}{\text { Main Hours }}$} & \multirow[b]{3}{*}{ After Hours } \\
\hline & & & & & \multirow{2}{*}{$\begin{array}{c}\text { Main Hours Europe } \\
\text { Pre-Market US }\end{array}$} & \multirow{2}{*}{ Main Hours } & & \\
\hline & Pre-Market & Main Hours & Pre-Market & Main Hours & & & & \\
\hline & 00:00-01:00 & 01:00-08:00 & 08:00-09:00 & 09:00-13:00 & 13:00-15:30 & $15: 30-17: 30$ & $17: 30-22: 00$ & 22:00-00:00 \\
\hline \multicolumn{9}{|l|}{ Equities } \\
\hline S\&P 500 (ES) & $0.83 \%$ & $2.49 \%$ & $0.69 \%$ & $6.21 \%$ & $7.55 \%$ & $34.77 \%$ & $39.28 \%$ & $8.66 \%$ \\
\hline EuroStoxx $50(\mathrm{XX})$ & - & - & $2.46 \%$ & $34.84 \%$ & $16.71 \%$ & $28.68 \%$ & $17.03 \%$ & $0.28 \%$ \\
\hline Nikkei (NK) & $0.71 \%$ & $8.30 \%$ & $2.80 \%$ & $18.43 \%$ & $12.55 \%$ & $27.20 \%$ & $26.09 \%$ & $4.40 \%$ \\
\hline \multicolumn{9}{|l|}{ Bonds } \\
\hline 10y US T-Note (TY) & $0.80 \%$ & $3.80 \%$ & $1.77 \%$ & $11.81 \%$ & $22.02 \%$ & $27.76 \%$ & $30.89 \%$ & $1.60 \%$ \\
\hline 10y German Bund (BN) & - & - & $5.36 \%$ & $39.27 \%$ & $23.76 \%$ & $24.58 \%$ & $6.98 \%$ & $0.07 \%$ \\
\hline 10y Japanese Bond (JB) & $1.67 \%$ & $86.37 \%$ & $4.65 \%$ & $6.64 \%$ & $0.72 \%$ & $0.19 \%$ & - & - \\
\hline \multicolumn{9}{|l|}{ Currencies } \\
\hline EUR/USD (EC) & $0.99 \%$ & $7.04 \%$ & $3.22 \%$ & $22.76 \%$ & $20.75 \%$ & $25.65 \%$ & $19.18 \%$ & $0.89 \%$ \\
\hline JPY/USD (JY) & $1.35 \%$ & $16.07 \%$ & $3.44 \%$ & $18.23 \%$ & $18.68 \%$ & $22.39 \%$ & $19.39 \%$ & $0.96 \%$ \\
\hline \multicolumn{9}{|l|}{ Oil } \\
\hline WTI Oil (CL) & $0.84 \%$ & $3.32 \%$ & $0.82 \%$ & $7.37 \%$ & $15.78 \%$ & $32.26 \%$ & $39.09 \%$ & $0.92 \%$ \\
\hline Brent Oil (CO) & $0.42 \%$ & $1.84 \%$ & $1.01 \%$ & $22.67 \%$ & $16.58 \%$ & $25.79 \%$ & $31.64 \%$ & $0.43 \%$ \\
\hline \multicolumn{9}{|l|}{ Metals } \\
\hline Gold (GC) & $1.33 \%$ & $10.23 \%$ & $2.59 \%$ & $13.77 \%$ & $19.89 \%$ & $27.35 \%$ & $24.14 \%$ & $1.15 \%$ \\
\hline Copper (HG) & $1.05 \%$ & $15.08 \%$ & $3.57 \%$ & $13.95 \%$ & $20.21 \%$ & $24.93 \%$ & $21.04 \%$ & $0.64 \%$ \\
\hline Silver (SV) & $1.30 \%$ & $8.37 \%$ & $2.25 \%$ & $11.99 \%$ & $20.69 \%$ & $28.46 \%$ & $26.37 \%$ & $0.99 \%$ \\
\hline
\end{tabular}

This table reports the share of overall volume transacted during different periods of the day. The periods were defined to capture the pre-market and main hours of the three global financial centers Japan, Europe, and the US (see Section 3 for details). All listed time periods are left-closed and right-open time intervals in CET. 
Table 3

Price Contribution during the Trading Day

\begin{tabular}{|c|c|c|c|c|c|c|c|c|}
\hline \multirow{4}{*}{ Futures Contract } & \multirow{2}{*}{\multicolumn{2}{|c|}{ Japan }} & \multicolumn{4}{|c|}{ Europe \& US } & \multirow{3}{*}{$\frac{\text { US }}{\text { Main Hours }}$} & \multirow[b]{3}{*}{ After Hours } \\
\hline & & & & ope & \multirow{2}{*}{$\begin{array}{l}\text { Main Hours Europe } \\
\text { Pre-Market US }\end{array}$} & \multirow{2}{*}{ Main Hours } & & \\
\hline & Pre-Market & Main Hours & Pre-Market & Main Hours & & & & \\
\hline & 00:00-01:00 & 01:00-08:00 & 08:00-09:00 & 09:00-13:00 & 13:00-15:30 & $15: 30-17: 30$ & $17: 30-22: 00$ & $22: 00-00: 00$ \\
\hline \multicolumn{9}{|l|}{ Equities } \\
\hline S\&P 500 (ES) & $-2.02 \%$ & $3.70 \%$ & $2.69 \%$ & $35.87 \%^{c}$ & $5.16 \%$ & $-11.54 \%$ & $47.52 \%^{c}$ & $19.04 \%^{c}$ \\
\hline EuroStoxx $50(\mathrm{XX})$ & - & - & $18.18 \%^{b}$ & $26.14 \%^{c}$ & $18.01 \%^{b}$ & $9.50 \%$ & $27.15 \%^{c}$ & $1.09 \%$ \\
\hline Nikkei (NK) & $7.41 \%^{b}$ & $45.42 \%^{c}$ & $1.35 \%$ & $10.19 \%^{b}$ & $4.75 \%$ & $17.19 \%^{c}$ & $19.35 \%^{c}$ & $-5.09 \%$ \\
\hline \multicolumn{9}{|l|}{ Bonds } \\
\hline 10y US T-Note (TY) & $10.20 \%^{c}$ & $6.84 \%^{a}$ & $2.54 \%$ & $7.78 \%$ & $35.15 \%^{c}$ & $7.00 \% c$ & $21.33 \%^{c}$ & $-0.32 \%$ \\
\hline 10y German Bund (BN) & - & - & $8.05 \%$ & $41.38 \%^{c}$ & $22.59 \%^{c}$ & $18.17 \%^{c}$ & $10.00 \%^{b}$ & $-0.16 \%$ \\
\hline 10y Japanese Bond (JB) & $4.55 \%^{c}$ & $76.60 \%^{c}$ & $6.35 \%^{c}$ & $7.18 \%^{b}$ & $3.63 \%^{b}$ & $1.83 \%^{a}$ & - & - \\
\hline \multicolumn{9}{|l|}{ Currencies } \\
\hline EUR/USD (EC) & $6.24 \%$ & $10.08 \%^{a}$ & $8.08 \%^{a}$ & $22.45 \%^{b}$ & $20.13 \%^{c}$ & $24.67 \%^{c}$ & $8.92 \%$ & $-0.43 \%$ \\
\hline JPY/USD (JY) & $5.95 \%$ & $29.65 \%^{c}$ & $7.01 \%^{a}$ & $37.38 \%^{c}$ & $14.69 \%^{b}$ & $4.35 \%$ & $6.96 \%$ & $-5.38 \%$ \\
\hline \multicolumn{9}{|l|}{ Oil } \\
\hline WTI Oil (CL) & $-25.70 \%$ & $-11.41 \%$ & $8.75 \%$ & $32.21 \%^{a}$ & $23.46 \%^{b}$ & $47.25 \%^{b}$ & $16.12 \%$ & $9.52 \%^{b}$ \\
\hline Brent Oil $(\mathrm{CO})$ & $-1.02 \%$ & $6.85 \%$ & $-5.05 \%$ & $28.00 \%^{b}$ & $42.95 \%^{b}$ & $18.49 \%$ & $8.87 \%$ & $1.15 \%$ \\
\hline \multicolumn{9}{|l|}{ Metals } \\
\hline Gold (GC) & $2.29 \%$ & $6.73 \%$ & $5.49 \%^{a}$ & $16.24 \%^{c}$ & $23.75 \%^{c}$ & $28.89 \%^{c}$ & $17.07 \%^{b}$ & $-0.21 \%$ \\
\hline Copper (HG) & $-4.99 \%$ & $20.22 \%$ & $16.06 \%^{b}$ & $30.61 \%^{b}$ & $-20.10 \%$ & $39.02 \%^{c}$ & $32.39 \%^{a}$ & $-12.70 \%$ \\
\hline Silver (SV) & $3.52 \%$ & $30.01 \%^{c}$ & $2.43 \%$ & $9.91 \%$ & $20.77 \%^{b}$ & $19.01 \%$ & $9.17 \%$ & $5.72 \%^{a}$ \\
\hline
\end{tabular}

This table reports the relative price contribution during different periods of the day. The periods were defined to capture the pre-market and main hours of the three global financial centers Japan, Europe, and the US (see Section 3 for details). All listed time periods are left-closed and right-open time intervals in CET. For each period $i$ during the trading day, the price contribution is computed as $P C_{i}=\frac{r_{i}}{r}$, where $r_{i}$ denotes the return during period $i$ and $r$ the total return for the day. Price contribution is calculated for each day and then averaged across days. ${ }^{a},{ }^{b}$, and ${ }^{c}$ denote statistical significance (difference from zero) at the 10\%, $5 \%$ and $1 \%$-level, respectively. 
Table 4

Volume-Weighted Price Contribution during the Trading Day

\begin{tabular}{|c|c|c|c|c|c|c|c|c|}
\hline \multirow{4}{*}{ Futures Contract } & \multirow{2}{*}{\multicolumn{2}{|c|}{ Japan }} & \multirow{2}{*}{\multicolumn{2}{|c|}{ Europe }} & \multicolumn{2}{|c|}{ Europe \& US } & \multirow{3}{*}{$\frac{\text { US }}{\text { Main Hours }}$} & \multirow[b]{3}{*}{ After Hours } \\
\hline & & & & & \multirow{2}{*}{$\begin{array}{c}\text { Main Hours Europe } \\
\text { Pre-Market US }\end{array}$} & \multirow{2}{*}{ Main Hours } & & \\
\hline & Pre-Market & Main Hours & Pre-Market & Main Hours & & & & \\
\hline & 00:00-01:00 & 01:00-08:00 & 08:00-09:00 & 09:00-13:00 & $13: 00-15: 30$ & $15: 30-17: 30$ & $17: 30-22: 00$ & 22:00-00:00 \\
\hline \multicolumn{9}{|l|}{ Equities } \\
\hline $\mathrm{S} \& \mathrm{P} 500(\mathrm{ES})$ & 0.11 & 2.99 & 7.45 & $5.27^{c}$ & 0.11 & -0.44 & $1.19^{b}$ & $2.19^{c}$ \\
\hline EuroStoxx 50 (XX) & - & - & $5.67^{b}$ & $0.75^{c}$ & $0.89^{b}$ & 0.26 & $1.67^{c}$ & 5.11 \\
\hline Nikkei (NK) & $170.90^{b}$ & $25.46^{b}$ & 8.30 & 0.45 & 0.18 & $0.65^{c}$ & 0.20 & -2.13 \\
\hline \multicolumn{9}{|l|}{ Bonds } \\
\hline 10y US T-Note (TY) & 12.26 & 1.70 & 1.60 & $0.84^{a}$ & $1.44^{c}$ & $0.46^{b}$ & -0.23 & 0.60 \\
\hline 10y German Bund (BN) & - & - & 1.05 & $1.01^{c}$ & $0.83^{c}$ & $0.77^{c}$ & 0.86 & -3.23 \\
\hline 10y Japanese Bond (JB) & $0.36^{a}$ & $0.88^{c}$ & $1.15^{b}$ & $0.79^{a}$ & $2.96^{a}$ & 3.23 & - & - \\
\hline \multicolumn{9}{|l|}{ Currencies } \\
\hline EUR/USD (EC) & $7.86^{a}$ & 0.83 & $2.67^{b}$ & $0.97^{c}$ & $0.84^{b}$ & $0.80^{c}$ & $1.26^{b}$ & 1.48 \\
\hline JPY/USD (JY) & 0.33 & $1.84^{c}$ & $1.76^{a}$ & $1.89^{c}$ & 0.37 & -0.10 & 1.60 & -6.86 \\
\hline \multicolumn{9}{|l|}{ Oil } \\
\hline WTI Oil (CL) & -22.38 & -3.24 & 2.02 & $3.77^{a}$ & $1.32^{a}$ & $1.22^{a}$ & $0.58^{a}$ & $11.00^{a}$ \\
\hline Brent Oil (CO) & -2.91 & $6.83^{a}$ & -10.26 & $1.11^{b}$ & $2.36^{b}$ & 0.31 & 0.29 & 11.57 \\
\hline \multicolumn{9}{|l|}{ Metals } \\
\hline Gold (GC) & 3.42 & 0.22 & 0.73 & $1.04^{b}$ & $0.94^{b}$ & $0.93^{c}$ & $0.85^{b}$ & 1.30 \\
\hline Copper (HG) & -0.21 & 1.44 & $4.17^{a}$ & $1.88^{b}$ & -0.62 & $1.42^{b}$ & 1.15 & -17.35 \\
\hline Silver (SV) & 4.41 & $3.08^{b}$ & -0.42 & 1.00 & $0.67^{a}$ & 0.49 & 0.49 & $6.13^{a}$ \\
\hline
\end{tabular}

This table reports volume-weighted relative price contribution during different periods of the day. The periods were defined to capture the premarket and main hours of the three global financial centers Japan, Europe, and the US (see Section 3 for details). All listed time periods are left-closed and right-open time intervals in CET. For each period $i$ during the trading day, the volume-weighted price contribution is computed as $V W P C_{i}=\frac{r_{i} / r}{V_{i} / V}$, where $r_{i}$ denotes the return during period $i, r$ the total return for the day, $V_{i}$ trading volume during period $i$ and $V$ total daily volume. Volume-weighted price contribution is calculated for each day and then averaged across days. ${ }^{a},{ }^{b}$, and ${ }^{c}$ denote statistical significance (difference from zero) at the $10 \%, 5 \%$ and $1 \%$-level, respectively. 
Table 5

Variance Contribution during the Trading Day

\begin{tabular}{|c|c|c|c|c|c|c|c|c|}
\hline \multirow{4}{*}{ Futures Contract } & \multirow{2}{*}{\multicolumn{2}{|c|}{ Japan }} & \multirow{2}{*}{\multicolumn{2}{|c|}{ Europe }} & \multicolumn{2}{|c|}{ Europe \& US } & \multirow{3}{*}{$\frac{\text { US }}{\text { Main Hours }}$} & \multirow[b]{3}{*}{ After Hours } \\
\hline & & & & & \multirow{2}{*}{$\begin{array}{c}\text { Main Hours Europe } \\
\text { Pre-Market US }\end{array}$} & \multirow{2}{*}{ Main Hours } & & \\
\hline & Pre-Market & Main Hours & Pre-Market & Main Hours & & & & \\
\hline & 00:00-01:00 & 01:00-08:00 & 08:00-09:00 & 09:00-13:00 & 13:00-15:30 & $15: 30-17: 30$ & $17: 30-22: 00$ & $22: 00-00: 00$ \\
\hline \multicolumn{9}{|l|}{ Equities } \\
\hline S\&P 500 (ES) & $2.64 \%$ & $11.59 \%$ & $2.38 \%$ & $14.55 \%$ & $11.91 \%$ & $23.82 \%$ & $28.96 \%$ & $4.66 \%$ \\
\hline EuroStoxx 50 (XX) & - & - & $14.03 \%$ & $32.50 \%$ & $15.81 \%$ & $20.68 \%$ & $16.49 \%$ & $0.55 \%$ \\
\hline Nikkei (NK) & $5.76 \%$ & $38.29 \%$ & $4.48 \%$ & $13.32 \%$ & $7.43 \%$ & $11.26 \%$ & $16.02 \%$ & $3.98 \%$ \\
\hline \multicolumn{9}{|l|}{ Bonds } \\
\hline 10y US T-Note (TY) & $3.54 \%$ & $12.01 \%$ & $3.48 \%$ & $16.10 \%$ & $21.91 \%$ & $17.01 \%$ & $24.69 \%$ & $1.78 \%$ \\
\hline 10y German Bund (BN) & - & - & $15.21 \%$ & $32.84 \%$ & $20.48 \%$ & $18.67 \%$ & $12.56 \%$ & $0.30 \%$ \\
\hline 10y Japanese Bond (JB) & $3.40 \%$ & $71.45 \%$ & $4.78 \%$ & $12.34 \%$ & $5.98 \%$ & $2.18 \%$ & - & - \\
\hline \multicolumn{9}{|l|}{ Currencies } \\
\hline EUR/USD (EC) & $4.11 \%$ & $15.01 \%$ & $5.01 \%$ & $23.93 \%$ & $17.62 \%$ & $17.12 \%$ & $16.36 \%$ & $1.37 \%$ \\
\hline JPY/USD (JY) & $5.75 \%$ & $24.18 \%$ & $4.07 \%$ & $17.75 \%$ & $16.47 \%$ & $14.90 \%$ & $15.20 \%$ & $2.26 \%$ \\
\hline \multicolumn{9}{|l|}{ Oil } \\
\hline WTI Oil (CL) & $3.12 \%$ & $9.39 \%$ & $2.05 \%$ & $13.98 \%$ & $18.06 \%$ & $23.45 \%$ & $28.85 \%$ & $1.54 \%$ \\
\hline Brent Oil (CO) & $1.88 \%$ & $11.18 \%$ & $2.39 \%$ & $18.46 \%$ & $15.78 \%$ & $20.98 \%$ & $27.80 \%$ & $1.85 \%$ \\
\hline \multicolumn{9}{|l|}{ Metals } \\
\hline Gold (GC) & $3.98 \%$ & $14.42 \%$ & $2.71 \%$ & $14.23 \%$ & $20.32 \%$ & $21.90 \%$ & $21.29 \%$ & $1.63 \%$ \\
\hline Copper (HG) & $4.87 \%$ & $25.22 \%$ & $3.75 \%$ & $16.38 \%$ & $16.20 \%$ & $16.99 \%$ & $15.35 \%$ & $1.77 \%$ \\
\hline Silver (SV) & $4.43 \%$ & $16.20 \%$ & $3.03 \%$ & $14.00 \%$ & $19.23 \%$ & $20.30 \%$ & $21.60 \%$ & $1.70 \%$ \\
\hline
\end{tabular}

This table reports the relative variance contribution during different periods of the day. The periods were defined to capture the pre-market and main hours of the three global financial centers Japan, Europe, and the US (see Section 3 for details). All listed time periods are left-closed and right-open time intervals in CET. For each period during the trading day, the variance contribution is computed as the sum of the squared returns across all five-minute intervals falling in a given period (plus the squared open return if the market opened at the beginning or during the period in question) divided by the sum of all squared returns for the day. The variance contribution is calculated for each day and then averaged across days. 
Table 6

Scheduled US News Announcements

\begin{tabular}{lccc}
\hline Announcements & Frequency & Source & Time (CET) \\
\hline $1^{\text {st }}$ Announcements & & & \\
Consumer Price Index & Monthly & Bureau of Labor Statistics & $14: 30$ \\
Durable Goods Orders & Monthly & US Census Bureau & $14: 30$ \\
Gross Domestic Product & Monthly & Bureau of Economic Analysis & $14: 30$ \\
Initial Jobless Claims & Weekly & Department of Labor & $14: 30$ \\
Non-Farm Payroll Employment & Monthly & Bureau of Labor Statistics & $14: 30$ \\
Producer Price Index & Monthly & Bureau of Labor Statistics & $14: 30$ \\
Retails Sales Less Automotive & Monthly & US Census Bureau & $14: 30$ \\
\hline $2^{n d}$ Announcements & \multicolumn{3}{|}{} \\
Consumer Confidence Index & Monthly & Conference Board & $16: 00$ \\
ISM Manufacturing Index & Monthly & Inst. for Supply Management & $16: 00$ \\
ISM Non-Manuf. Index & Monthly & Inst. for Supply Management & $16: 00$ \\
Leading Indicators & Monthly & Conference Board & $16: 00$ \\
New Home Sales & Monthly & US Census Bureau & $16: 00$ \\
\hline $3^{r d}$ Announcement & & & \\
Federal Reserve Beige Book & Eight & Federal Reserve Bank & $20: 00$ \\
FOMC Rate Decision & times per & Federal Reserve Bank & $20: 00 / 20: 15$ \\
FOMC Meeting Minutes & year & Federal Reserve Bank & $20: 00$ \\
FOMC Meeting Press Conference & & Federal Reserve Bank & $20: 30-45$ \\
\hline
\end{tabular}

This table reports the most important scheduled US news announcements (divided into three chronologically ordered groups). The time of FOMC Rate Decision announcements changed during our sample period (20:15 CET until March 2013 and 20:00 CET afterwards). The beginning of the chairman/chairwoman's press conference is scheduled at approximately 20:30 CET. 
Table 7

Jumps at Times of Scheduled US News Announcements

\begin{tabular}{|c|c|c|c|c|c|c|c|c|}
\hline \multirow{2}{*}{ Futures Contract } & \multicolumn{2}{|c|}{$1^{\text {st }}$ Announcements } & \multicolumn{2}{|c|}{$2^{\text {nd }}$ Announcements } & \multicolumn{3}{|c|}{$3^{\text {rd }}$ Announcement } & \multirow{2}{*}{$\begin{array}{l}\text { Var. Contr. } \\
\text { Jumps (total) }\end{array}$} \\
\hline & Rank & Var. Contr. & Rank & Var. Contr. & Rank & Var. Contr. & Time (CET) & \\
\hline \multicolumn{9}{|l|}{ Equities } \\
\hline S\&P $500(\mathrm{ES})$ & 1 & $1.69 \%$ & 3 & $0.76 \%$ & 2 & $0.89 \%$ & $20.40-45$ & $6.89 \%$ \\
\hline EuroStoxx 50 (XX) & 1 & $0.78 \%$ & 3 & $0.39 \%$ & 2 & $0.50 \%$ & $20.40-45$ & $6.20 \%$ \\
\hline Nikkei (NK) & 3 & $0.29 \%$ & 21 & $0.05 \%$ & 4 & $0.26 \%$ & $20.40-45$ & $4.31 \%$ \\
\hline \multicolumn{9}{|l|}{ Bonds } \\
\hline 10y US T-Note (TY) & 1 & $4.77 \%$ & 3 & $0.68 \%$ & 4 & $0.49 \%$ & $20.00-05$ & $11.00 \%$ \\
\hline 10y German Bund (BN) & 1 & $1.54 \%$ & 3 & $0.18 \%$ & 6 & $0.10 \%$ & $20.00-05$ & $5.43 \%$ \\
\hline 10y Japanese Bond (JB) & - & $0.23 \%$ & - & - & - & - & - & $11.00 \%$ \\
\hline \multicolumn{9}{|l|}{ Currencies } \\
\hline EUR/USD (EC) & 1 & $0.69 \%$ & 5 & $0.19 \%$ & 4 & $0.20 \%$ & $20.15-20$ & $7.29 \%$ \\
\hline JPY/USD (JY) & 1 & $2.89 \%$ & 2 & $0.48 \%$ & 4 & $0.31 \%$ & $20.15-20$ & $12.59 \%$ \\
\hline \multicolumn{9}{|l|}{ Oil } \\
\hline WTI Oil (CL) & 2 & $0.48 \%$ & 4 & $0.23 \%$ & 6 & $0.23 \%$ & $20.25-30$ & $5.87 \%$ \\
\hline Brent Oil (CO) & 3 & $0.21 \%$ & 5 & $0.11 \%$ & 4 & $0.19 \%$ & $20.25-30$ & $5.00 \%$ \\
\hline \multicolumn{9}{|l|}{ Metals } \\
\hline Gold (GC) & 1 & $1.22 \%$ & 4 & $0.36 \%$ & 7 & $0.24 \%$ & $20.00-05$ & $10.34 \%$ \\
\hline Copper (HG) & 1 & $0.38 \%$ & 6 & $0.14 \%$ & 20 & $0.05 \%$ & $20.00-05$ & $4.98 \%$ \\
\hline Silver (SV) & 1 & $0.61 \%$ & 9 & $0.20 \%$ & 31 & $0.08 \%$ & $20.00-05$ & $9.57 \%$ \\
\hline
\end{tabular}

This table provides both the rank (in terms of size) and the average variance contribution (relative to average total daily return variance) of jumps occurring at the times corresponding to scheduled US news announcements listed in Table 6. Jumps associated with the opening of the market are ignored when determining the ranking. Since the times of announcements in the third group in Table 6 (FOMC Rate Decision, FOMC Meeting Minutes, Federal Reserve Beige Book and FOMC press conferences) changed during our sample period, the table only reports the variance of the largest jump over all possible five-minute intervals between 20:00-20:45 CET together with the time at which it occurs. The last column provides the total contribution of all jumps (including market opening jumps) to daily variance. For Japanese bond futures (JB) the $1^{\text {st }}$ announcements occur simultaneously with the reopening of the market (after an intraday trading halt) and the corresponding jump is therefore not ranked. Moreover, the market for JB is closed at the time of the $2^{\text {nd }}$ and $3^{\text {rd }}$ announcements. 

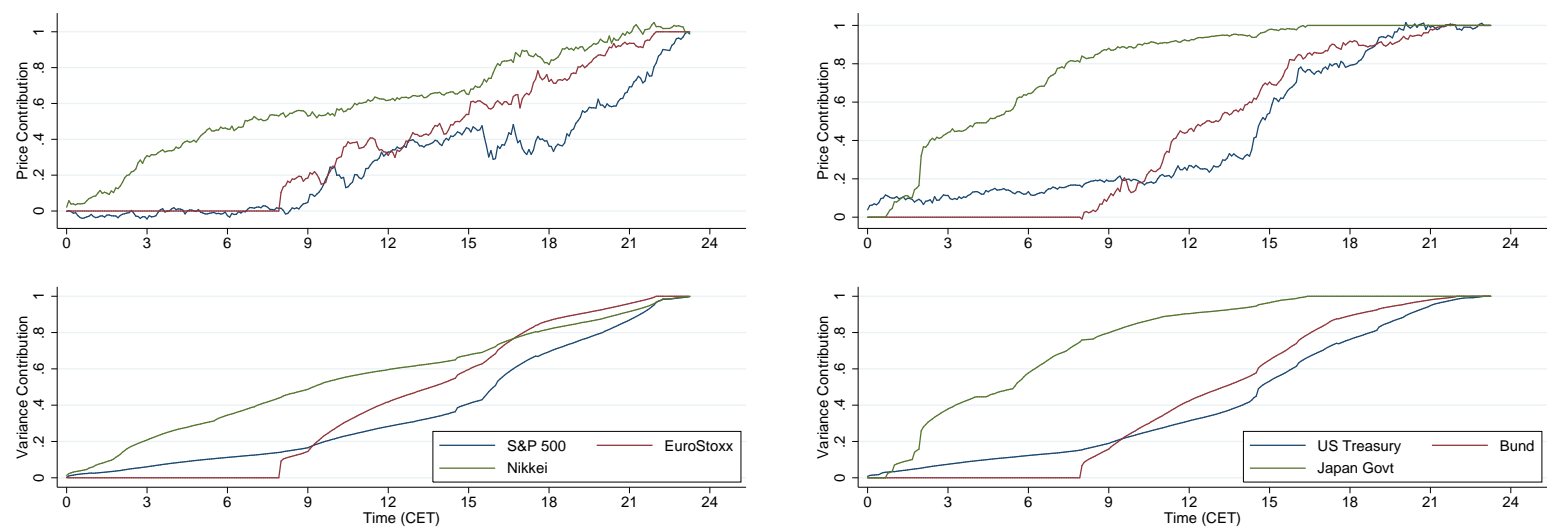

(a) Equities

(b) Bonds
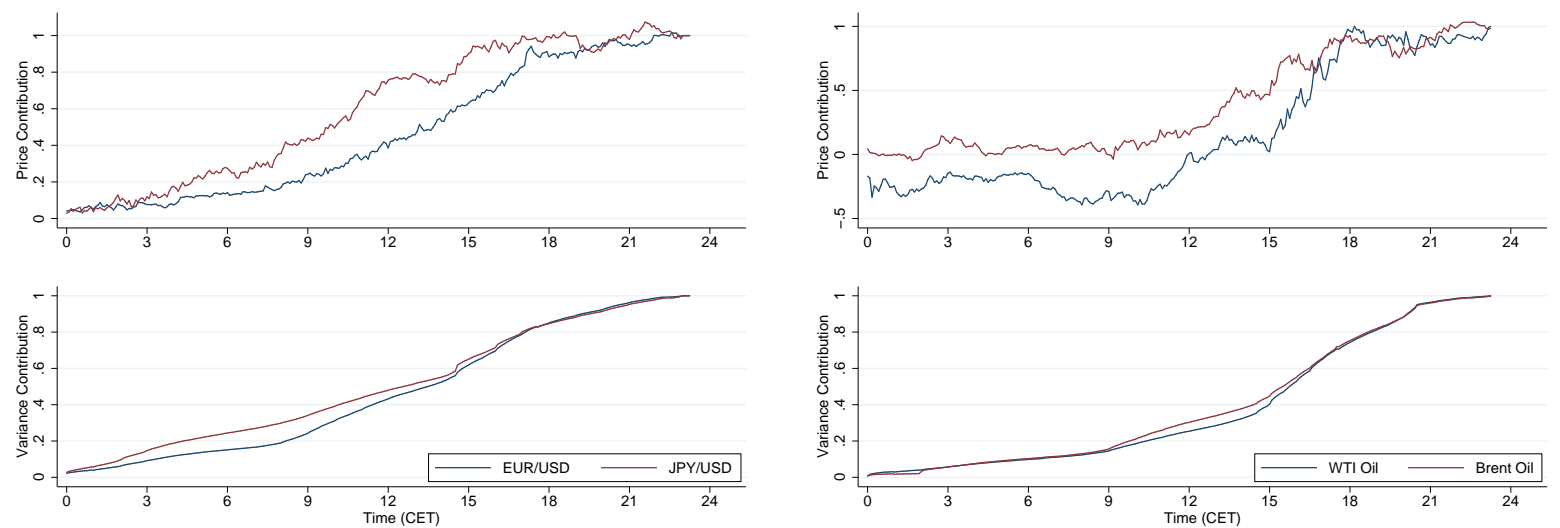

(c) Currencies

(d) Oil
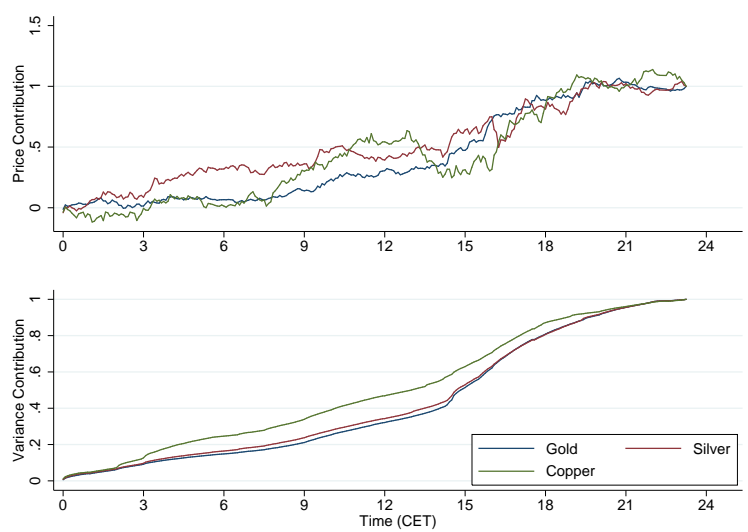

(e) Metals

\section{Figure 1}

\section{Cumulative price and variance contribution.}

This figure shows the cumulative price and variance contributions for each asset during the trading day. For each five-minute interval $i$ during the trading day, the price contribution is computed as $P C_{i}=\frac{r_{i}}{r}$, where $r_{i}$ denotes the return during interval $i$ and $r$ the total return for the day. The variance contribution is computed as the squared return for each interval $i$ divided by the sum of all squared returns for the day. Price and variance contribution are calculated for each day and then averaged across days. 

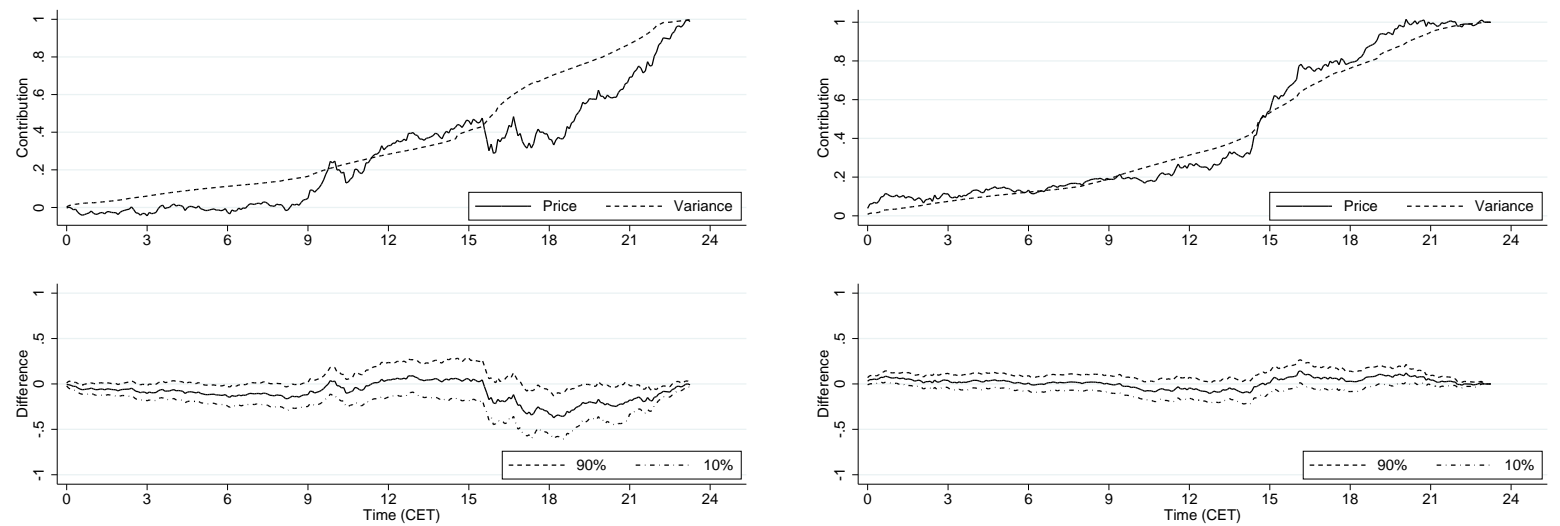

(a) $\mathrm{S} \& \mathrm{P} 500$

(b) US Treasury
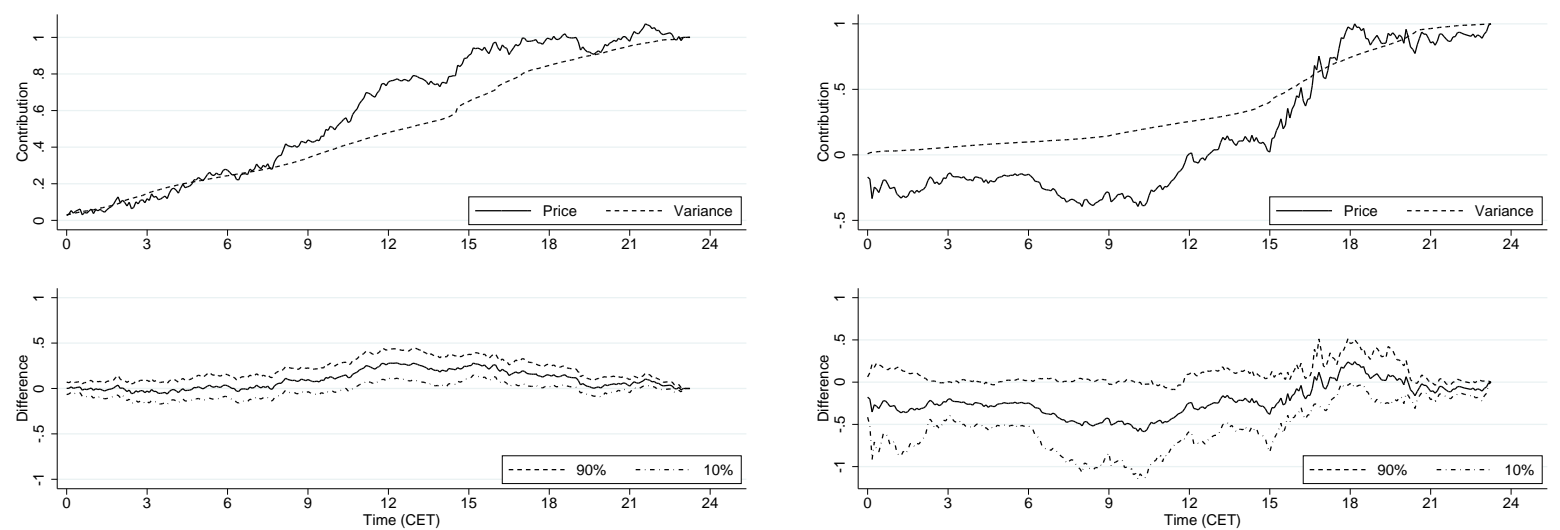

(c) JPY/USD

(d) WTI Oil
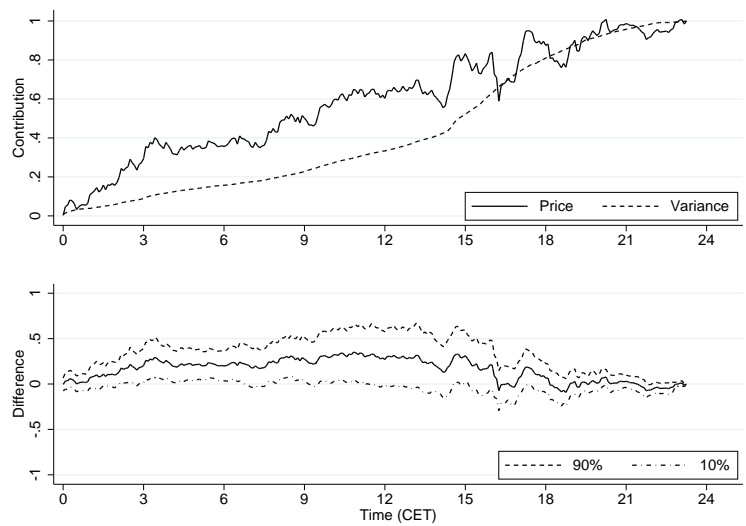

(e) Silver

Figure 2

Difference between price and variance contribution for selected assets.

This figure shows the cumulative price and variance contributions during the day, the difference between the two, as well as $90 \%$ confidence bounds for this difference. In each category, we select the asset for which the difference is largest. Price and variance contribution are computed for each day as described in Figure 1 and then averaged across days. The confidence intervals for the difference are obtained using its empirical distribution in the sample. 

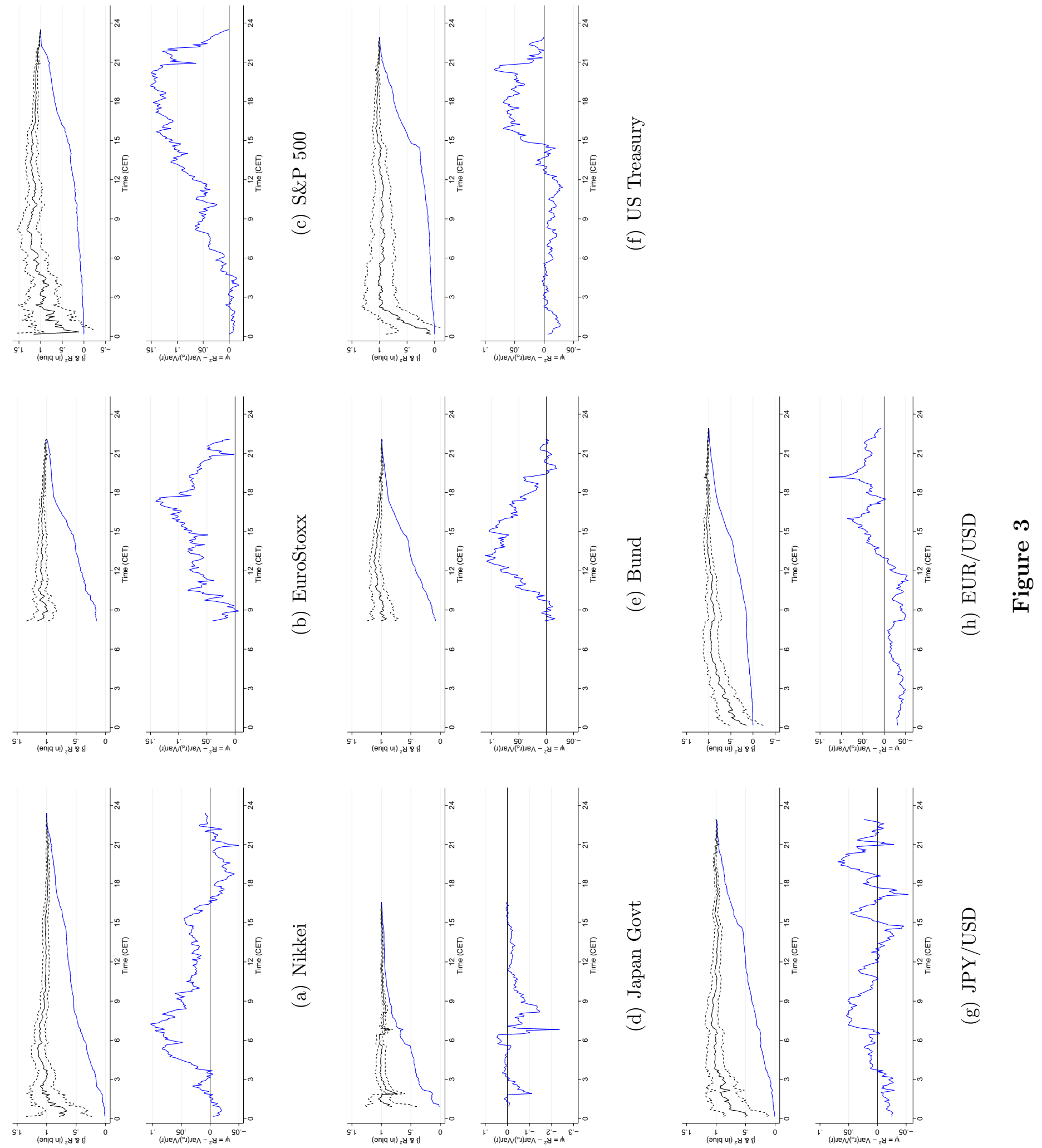

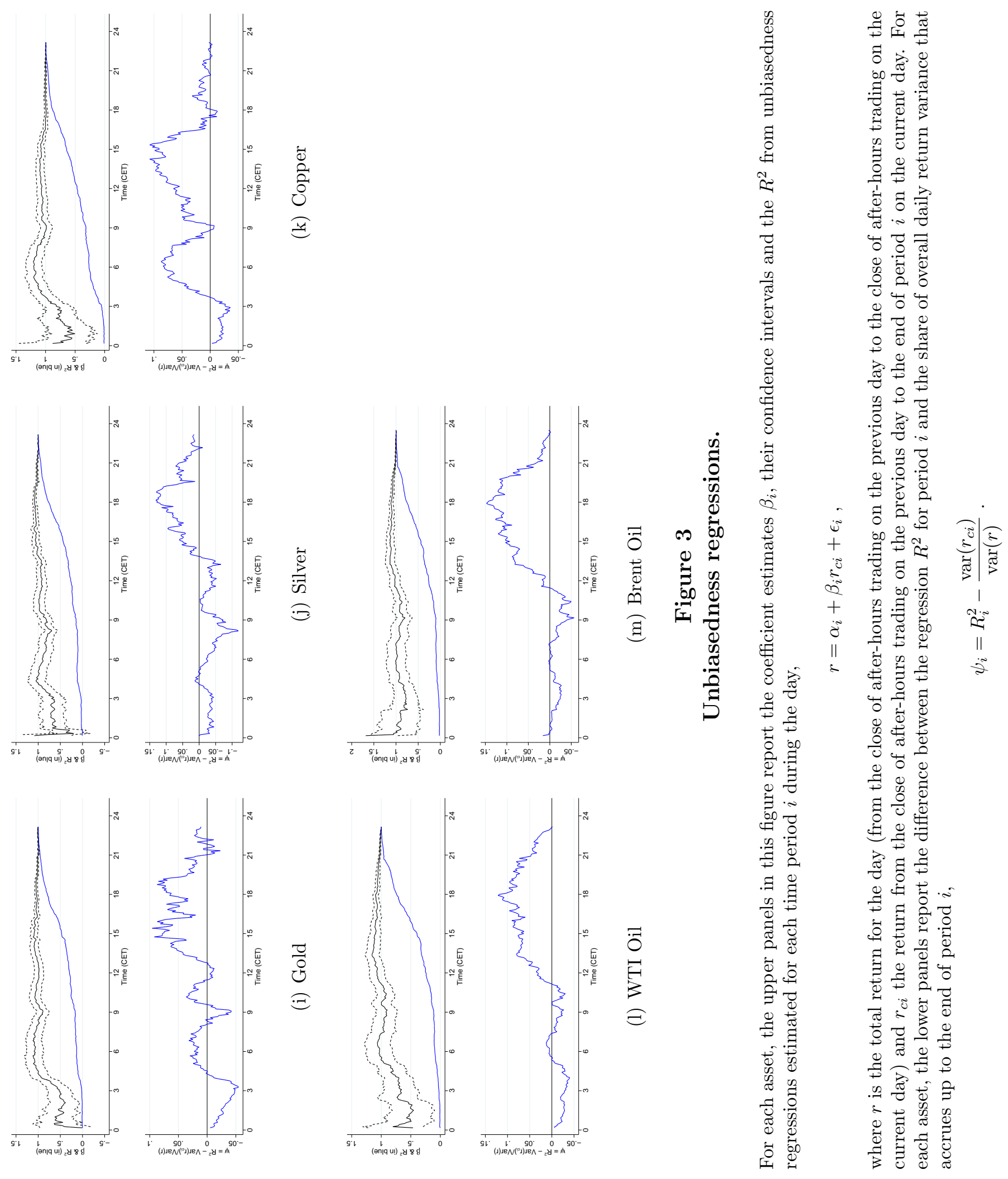


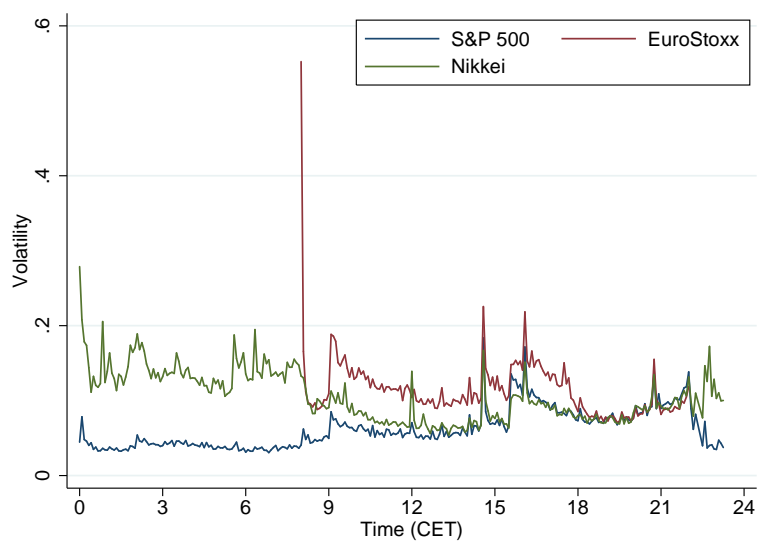

(a) Equities

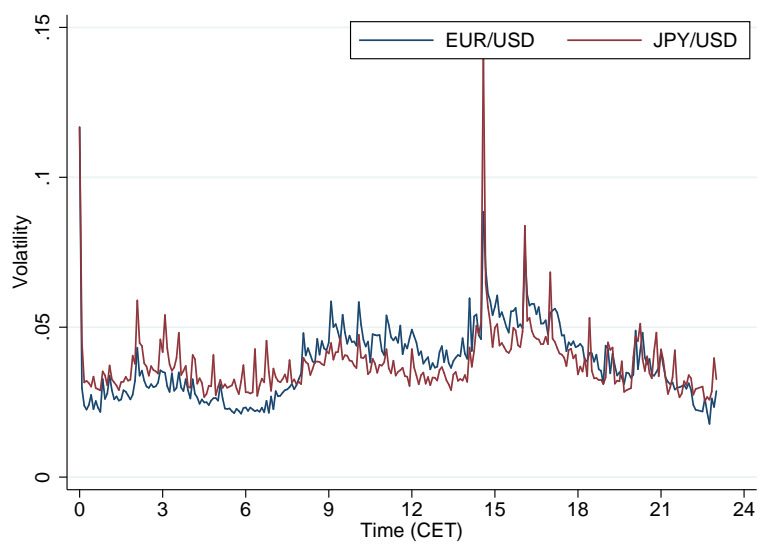

(c) Currencies

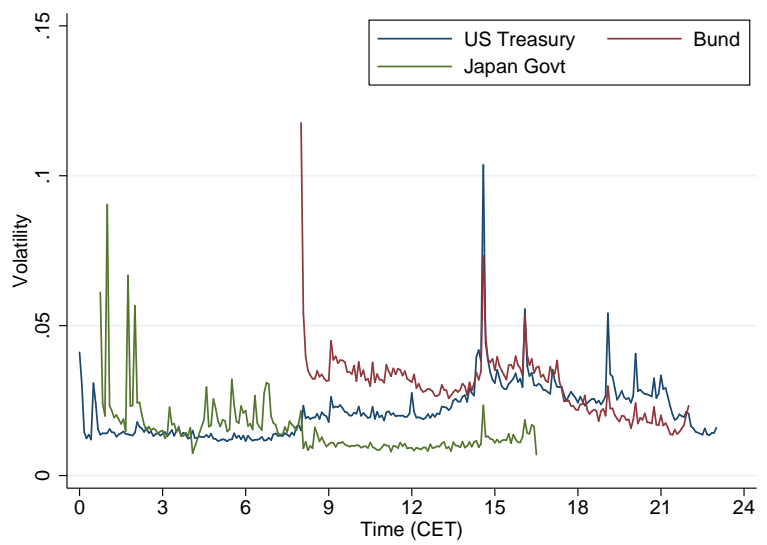

(b) Bonds

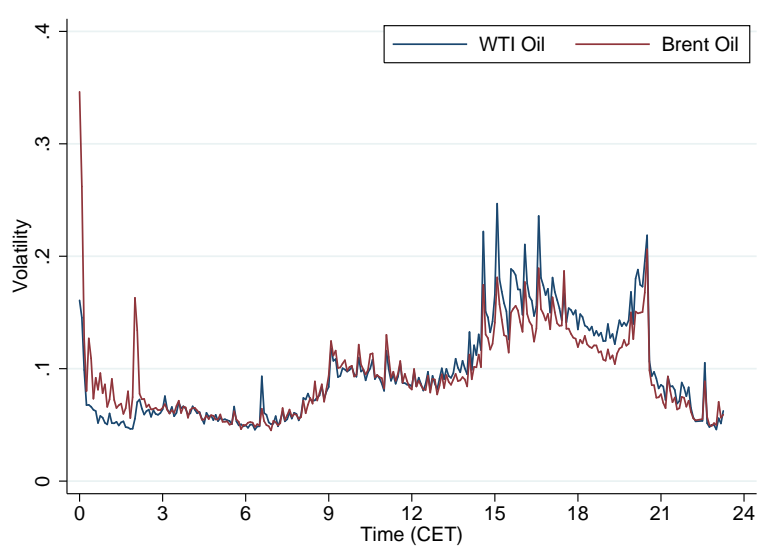

(d) Oil

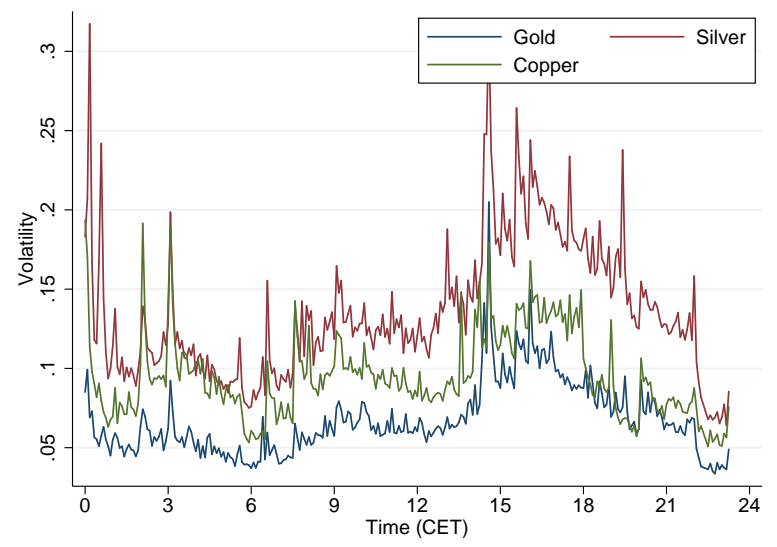

(e) Metals

Figure 4 Volatility during the trading day.

This figure shows the average return volatility of the different instruments for each five-minute interval during the trading day. Volatility is computed as the square root of the average squared return during each interval. 

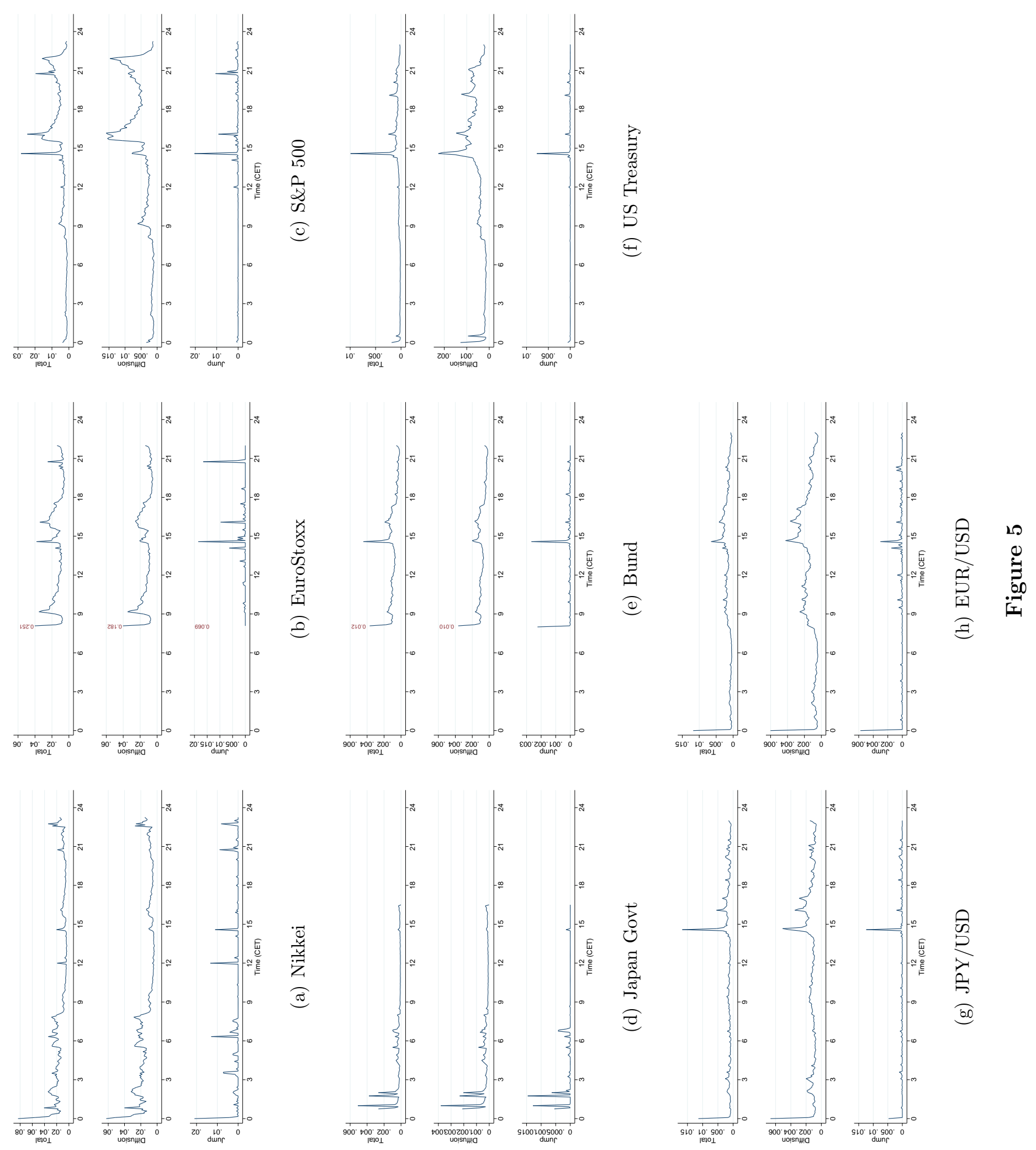

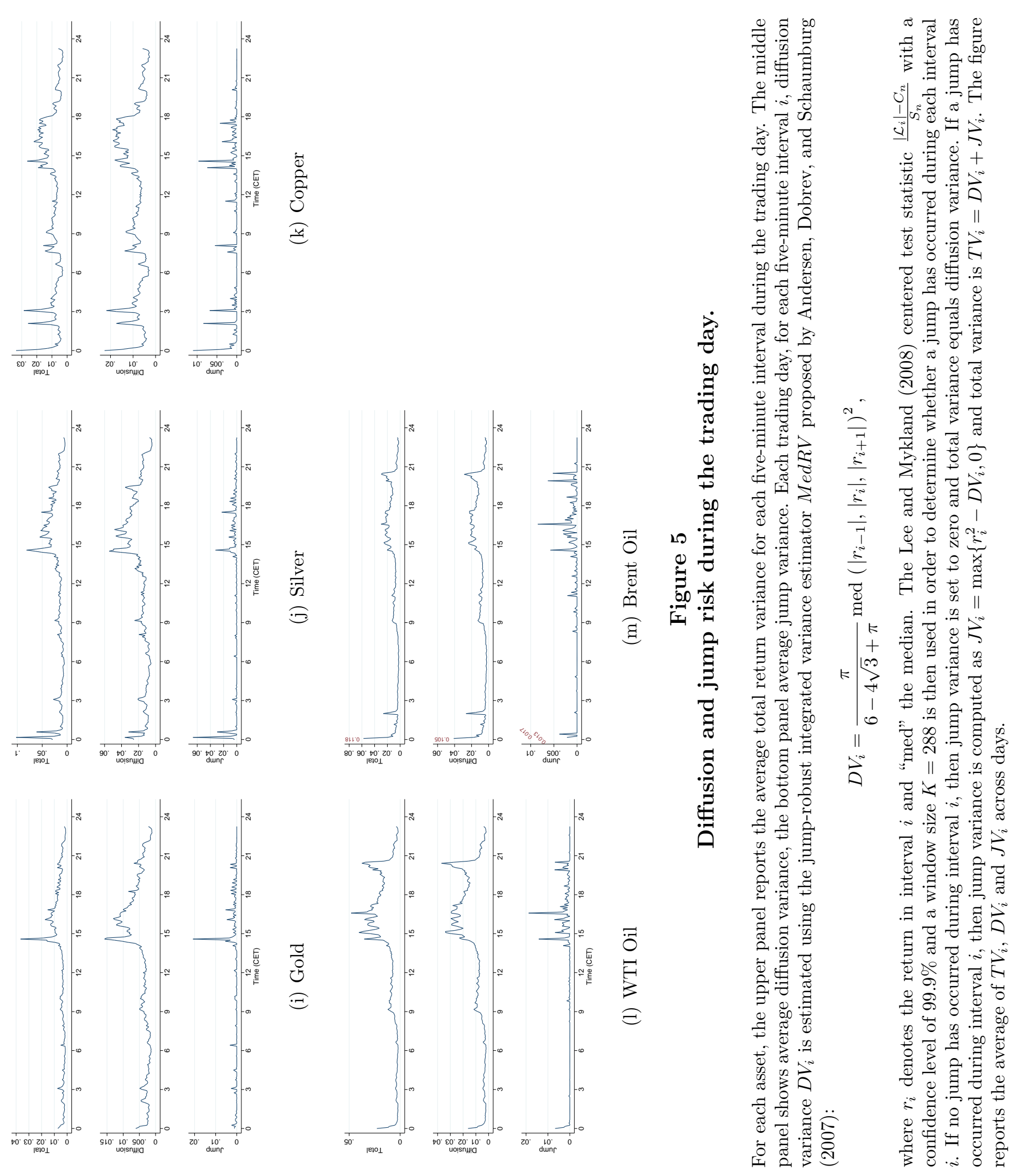

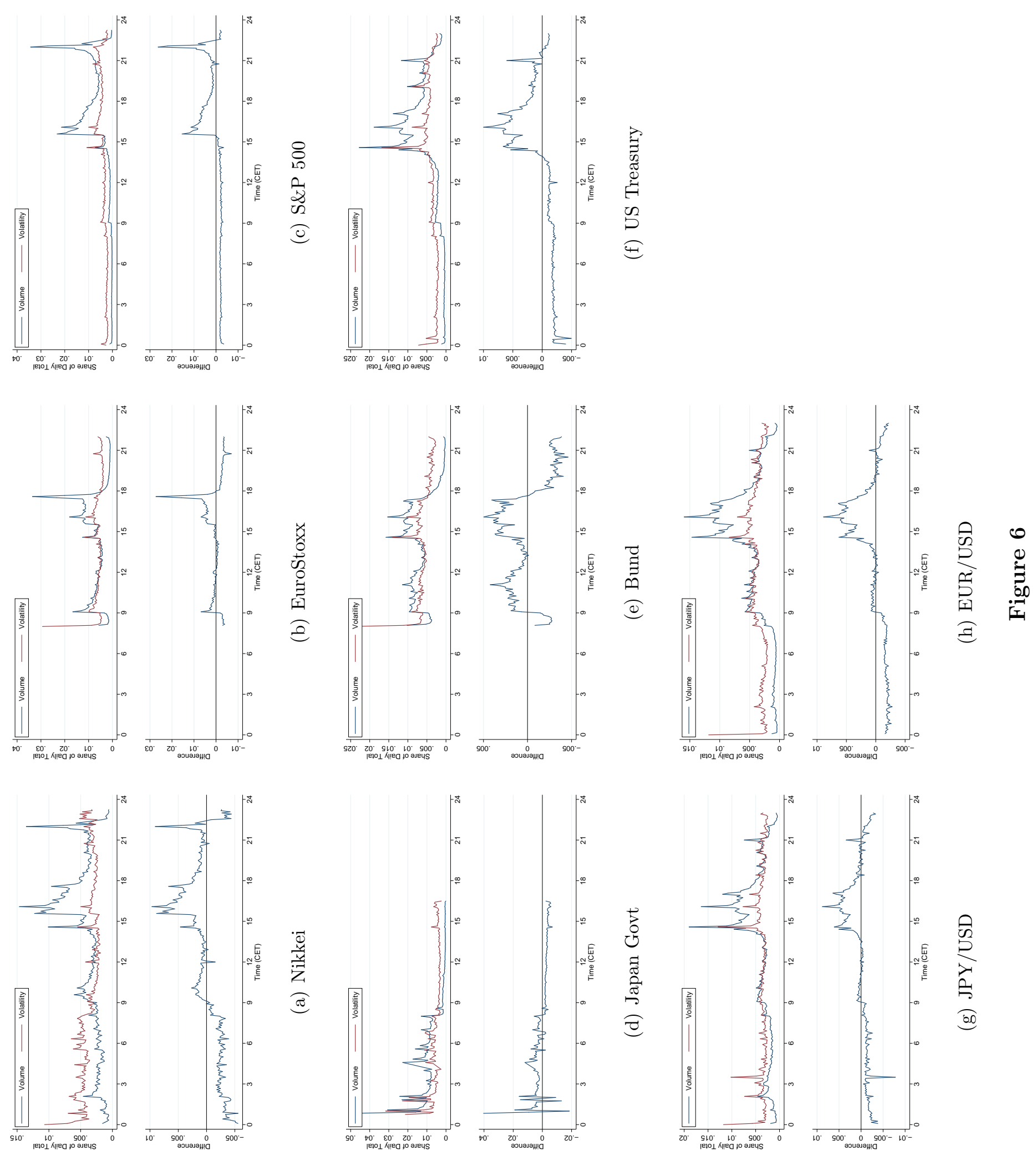

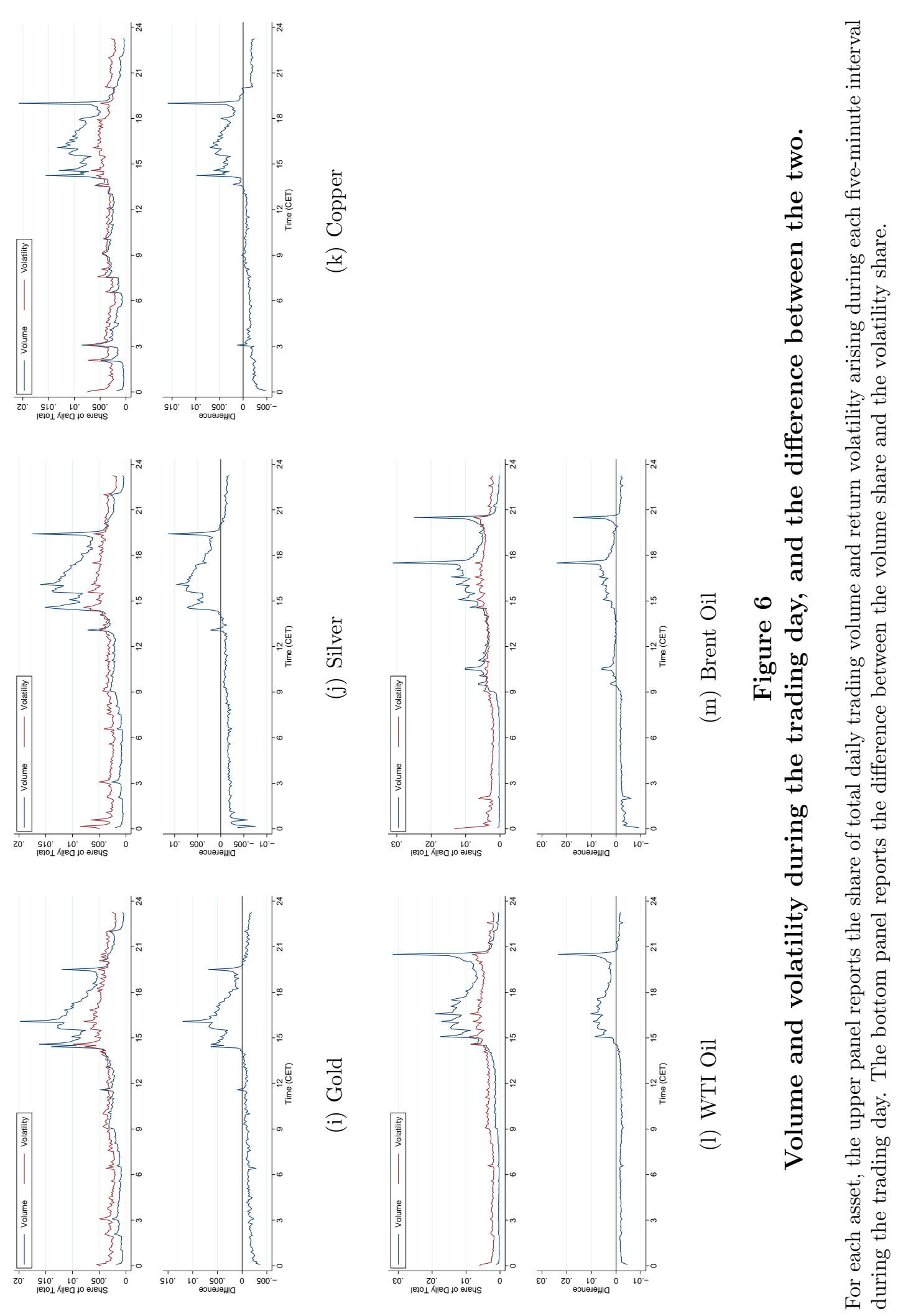